\title{
Preconditioning of Cardiosphere-Derived Cells With Hypoxia or Prolyl-4-Hydroxylase Inhibitors Increases Stemness and Decreases Reliance on Oxidative Metabolism
}

\author{
Suat Cheng Tan, ${ }^{*} \dagger$ Renata S. M. Gomes, ${ }^{*}$ Kar Kheng Yeoh, $¥ \S$ Filippo Perbellini, *ףI \\ Sophia Malandraki-Miller,* Lucy Ambrose, * Lisa C. Heather,* Giuseppe Faggian, đI \\ Christopher J. Schofield, $\$$ Kay E. Davies, $*$ Kieran Clarke, ${ }^{*}$ and Carolyn A. Carr* \\ *Department of Physiology, Anatomy and Genetics, University of Oxford, Oxford, UK \\ $\dagger$ School of Health Science, Health Campus, Universiti Sains Malaysia, Kelantan, Malaysia \\ $\ddagger$ Department of Chemistry, University of Oxford, Chemistry Research Laboratory, Oxford, UK \\ $\S$ School of Chemical Science, Universiti Sains Malaysia, Pulau Pinang, Malaysia \\ IIDepartment of Cardiac Surgery, University of Verona, Verona, Italy
}

\begin{abstract}
Cardiosphere-derived cells (CDCs), which can be isolated from heart explants, are a promising candidate cell source for infarcted myocardium regeneration. However, current protocols used to expand CDCs require at least 1 month in vitro to obtain sufficient cells for transplantation. We report that CDC culture can be optimized by preconditioning the cells under hypoxia ( $2 \%$ oxygen), which may reflect the physiological oxygen level of the stem cell niche. Under hypoxia, the CDC proliferation rate increased by 1.4 -fold, generating $6 \times 10^{6}$ CDCs with higher expression of cardiac stem cell and pluripotency gene markers compared to normoxia. Furthermore, telomerase (TERT), cytokines/ligands involved in stem cell trafficking (SDF/CXCR-4), erythropoiesis (EPO), and angiogenesis (VEGF) were increased under hypoxia. Hypoxic preconditioning was mimicked by treatment with two types of hypoxia-inducible factor (HIF) prolyl-4-hydroxylase inhibitors (PHDIs): dimethyloxaloylglycine (DMOG) and 2-(1-chloro-4-hydroxyisoquinoline-3-carboxamido) acetic acid (BIC). Despite the difference in specificity, both PHDIs significantly increased c-Kit expression and activated HIF, EPO, and CXCR-4. Furthermore, treatment with PHDIs for $24 \mathrm{~h}$ increased cell proliferation. Notably, all hypoxic and PHDI-preconditioned CDCs had decreased oxygen consumption and increased glycolytic metabolism. In conclusion, cells cultured under hypoxia could have potentially enhanced therapeutic potential, which can be mimicked, in part, by PHDIs.
\end{abstract}

Key words: Cardiac progenitor cells; Hypoxia-inducible factor (HIF); Hypoxic preconditioning; Dimethyloxaloylglycine (DMOG); 2-(1-Chloro-4-hydroxyisoquinoline-3-carboxamido) acetic acid (BIC)

\section{INTRODUCTION}

Cardiac stem cells (CSCs) were first identified within the heart in 2002 (25), challenging the generally accepted paradigm that the heart is a postmitotic organ $(2,61)$. A relatively low number of CSCs can be isolated using specific single cell markers, such as c-Kit (4) or Sca-1 $(49,64)$. In 2004, Messina et al. developed a method to isolate CSCs from human or murine hearts via the formation of cardiospheres (46), which could be further expanded in vitro to obtain sufficient cardiosphere-derived cells (CDCs) for transplantation (60). The CDCs were clonogenic, expressed stem and endothelial progenitor cell markers, appearing to have the properties of adult cardiac stem cells, and resulting in myocardial regeneration and functional improvement when injected into the infarcted rodent heart $(7,46,60)$. Johnston et al. have shown that administration of fewer than $10^{7} \mathrm{CDCs}$ to the porcine heart resulted in minimal long-term engraftment of donor cells (32); however, the culture protocol required at least 1 month to obtain sufficient CDCs for therapy, during which time the infarcted heart undergoes scar formation and remodeling (19). Furthermore, cells age during multiple in vitro passages, triggering variability of stem cell phenotypic and functional characteristics $(28,33,50,57)$. Therefore, CDCs would be more beneficial if they could be administered as soon as possible after infarction.

It has been shown by us and others that CDC transplantation resulted in significant myocardium regeneration

Received October 2, 2014; final acceptance February 25, 2015. Online prepub date: March 6, 2015.

Address correspondence to Dr. Suat Cheng Tan, School of Health Science, Health Campus, Universiti Sains Malaysia, 16150 Kubang Kerian, Kelantan, Malaysia. Tel: +609-7677776; Fax:+609-7677515; E-mail: tansc@usm.my 
and functional benefit for infarcted hearts, both in animal models and in clinical trials, yet donor cell retention is low, and complete recovery following CDC transplantation has not been fully accomplished $(7,27,44)$. Chimenti et al. demonstrated that paracrine mechanisms through the secretion of cytokines played a major role in the overall therapeutic potential of CDCs for myocardial infarction (10). Therefore, in this study, we aimed to optimize the CDC culture protocol not only to increase the cell proliferation rate but also to enhance the cells' therapeutic potential for myocardial infarction by conditioning the cells to a hypoxic environment under hypoxic culture or by stimulating the hypoxic response using two prolyl-4-hydroxylase inhibitors (PHDIs): dimethyloxaloylglycine (DMOG) and 2-(1-chloro-4-hydroxyisoquinoline-3-carboxamido) acetic acid (BIC) under normoxic condition.

Stem cells reside in complex microenvironments, termed niches, the nature of which play important roles in determining stem cell division, function, and differentiation $(39,54)$. To date, most tissue culture is routinely maintained at atmospheric levels of $21 \%$ oxygen, whereas the average oxygen concentration of tissue in vivo is about 2-9\%, with considerable variation based on location $(15,53,58)$. Adult stem cell niches are hypoxic, with oxygen levels as low as $1-2 \%$; thus, in vitro cultivation of stem cells in a traditional incubator supplied by room air does not recapitulate the in vivo physiological condition and could result in a gradual loss of primitive stem cell characteristics (15). Culture under low oxygen concentrations (2-6\% $\mathrm{O}_{2}$ ) enhances cell proliferation rates and reduces apoptosis in human and rat mesenchymal stem cells $(22,38)$, neural stem cells $(8,62,71)$, embryonic stem cells $(30,65)$, and adipose-derived stem cells $(36,52)$. Here we have isolated cardiac progenitors from the atria, which have been shown to be hypoxic (34), and cultured the cells under more physiologically relevant oxygen levels $\left(2 \% \mathrm{O}_{2}\right.$, termed hypoxia). The resulting changes in CDC self-renewal, differentiation, gene expression, and metabolism in vitro were investigated and compared with those cultured under atmospheric oxygen $\left(21 \% \mathrm{O}_{2}\right.$, termed normoxia).

Hypoxia triggers multiple physiological and cellular mechanisms that enable adaptation to reduced oxygen availability. Nonetheless, while oxygen concentration plays a major role in determining the efficiency of CDC culture, many processes involved in oxygen homeostasis also depend on the hypoxia-inducible factor (HIF) transcriptional complex and its inhibitory enzyme, prolyl-4hydroxylase (PHD), which requires 2-oxoglutarate (2OG) as a cosubstrate and iron as a cofactor $(3,41,66)$. Our hypothesis was that inhibition of any of these essential downregulators of HIF could potently activate the HIF response, mimicking hypoxic preconditioning. Therefore, in this study, we also investigated the effect of HIF activation using two PHD inhibitors (PHDIs). Our rationale for this study was that stimulating a hypoxic response by using PHDIs (pharmaceutical manipulation) may be more practical for large-scale culture than physiological manipulation of oxygen levels in vitro. In addition, these small cell-permeable inhibitors are specific in reaction, enabling the development of targeted inhibition of key downregulators of the HIF transcriptional complex in culture.

In understanding the activation process of the HIF system in the presence of PHDIs, it is important to understand the prolyl and asparaginyl hydroxylation pathway of the HIF system. The HIF transcriptional complex, which comprises HIF- $\alpha$ and HIF- $\beta$ subunits, was discovered by Semenza and Wang in 1992 (56). HIF- $\alpha$ protein is normally only detectable under hypoxic conditions, while HIF- $\beta$ protein is constitutively stable. Human HIF- $\alpha$ exists as three isoforms, of which the two best characterized, HIF- $1 \alpha$ and HIF- $2 \alpha$, each contain two sites of prolyl hydroxylation and one of asparaginyl hydroxylation (66). Prolyl hydroxylation occurs at residues Pro402 and Pro564 of human HIF-1 $\alpha$, as catalyzed by PHD isoforms (PHD 1-3), whereas asparaginyl hydroxylation occurs at Asn803 as catalyzed by FIH (factor-inhibiting HIF) (3). Both the PHDs and FIH are 2OG-dependent oxygenases, and their activity inhibits HIF-mediated transcription, but they act via different mechanisms. Prolyl hydroxylation by PHDs marks HIF-1 $\alpha$ for degradation by the von Hippel Lindau protein ( $\mathrm{pVHL}$ )-ubiquitin ligase system, which leads to proteasomal degradation of HIF- $\alpha$ protein, while asparaginyl hydroxylation by FIH within the HIF- $\alpha$ C-terminal transactivation domain (CAD) inhibits the interaction of CAD with CBP/p300 (Creb-binding protein/protein 300), which are transcriptional coactivators for many HIF target genes, thus reducing HIF-mediated expression. Under hypoxia, HIF- $\alpha$ escapes both prolyl and asparaginyl hydroxylation, HIF- $\alpha$ translocates to the nucleus and dimerizes with HIF-1 $\beta$ to form transcriptionally active heterodimeric HIF $(11,42)$.

Here we report the results of comparing the effects of two inhibitors, which each activated HIF via a different pathway: DMOG, a cell-permeable, competitive inhibitor of $2 \mathrm{OG}$ oxygenases (16), which also inhibits FIH, making it a non-PHD-specific inhibitor; and BIC [also reported as FG2216 (18)], a specific PHD inhibitor, which has been used in clinical trials as a proangiogenic compound acting via the HIF-1 $\alpha$ system (12). We also compared the effects of these inhibitors for HIF stabilization with hypoxic CDC culture and investigated whether pharmacological inhibition of PHDs successfully mimicked the effects of hypoxic preconditioning.

\section{MATERIALS AND METHODS}

\section{Animals}

Sprague-Dawley (SD) female rats were obtained from a commercial breeder (Harlan, Oxon, UK). Animals were 
kept under controlled conditions for temperature, humidity, and light, with water and rat chow available ad libitum. Rats were anesthetized with sodium pentobarbital (270 mg/kg body weight, IP; Euthatal, Merial, UK) to allow tissue removal. Body and heart weights were routinely recorded. All procedures were in accordance with Home Office (UK) guidelines under The Animals (Scientific Procedures) Act, 1986, and with University of Oxford, UK, institutional guidelines.

\section{Isolation and Expansion of CDCs}

Rat CDCs were cultured as previously described $(7,60)$ Briefly, SD rat hearts (4 months old) were excised, and heart weights were measured $(n=4)$. Atrial tissues were minced into $1-\mathrm{mm}^{2}$ explant fragments in $0.05 \%$ trypsinEDTA (Invitrogen). A total of 30 explant fragments of homogenous size were plated in each Petri dish precoated with fibronectin (Sigma-Aldrich). Then $2 \mathrm{ml}$ of complete explant medium (CEM) [Iscove's modified Dulbecco medium, IMDM (Invitrogen) supplemented with $20 \%$ fetal bovine serum, FBS (Invitrogen)] was added into each dish. The Petri dishes were equally divided between two incubators (Wolf Laboratories, UK) adjustable to different $\mathrm{O}_{2}$ concentrations by infusion of nitrogen $\left(\mathrm{N}_{2}\right)$. Normoxic cell culture was set at $21 \% \mathrm{O}_{2}$, whereas hypoxic cell culture was set at $2 \% \mathrm{O}_{2}$, both buffered with $5 \% \mathrm{CO}_{2}$. The $\mathrm{O}_{2}$ concentration was monitored continuously using an oxygen sensor (Wolf Laboratories). Supporting cells and phase bright cells [collectively known as explant-derived cells (EDCs)] grown out from the explants were harvested and resuspended in poly-D-lysine-coated 24-well plates with cardiosphere growth medium [CGM, 65\% Dulbecco's modified Eagle medium: nutrient mixture F-12 (DMEM/F12) (Invitrogen), 35\% IMDM, 7\% FBS added with 2\% B27 (Invitrogen), $25 \mathrm{ng} / \mathrm{ml}$ cardiotrophin (Peprotech), $10 \mathrm{ng} / \mathrm{ml}$ human recombinant epidermal growth factor (EGF; Promega), $20 \mathrm{ng} / \mathrm{ml}$ human recombinant fibroblast growth factor (FGF; Peprotech), and 5 units/ml thrombin (Sigma-Aldrich)] at a density of $3 \times 10^{4}$ cells per well. Cardiospheres were subsequently expanded in CEM on fibronectin-coated tissue culture flasks to generate CDCs, which were maintained in culture with CEM changed every 3 days and passaged every 5 days until passage $2(\mathrm{P} 2)$. All experiments in this study used P2 CDCs at $70 \%$ to $80 \%$ confluency, unless otherwise stated. For measurement of CDC proliferation, cell numbers and cell viability for every passage from passage 1 up to passage 5 were quantified using a dyeexclusion assay with trypan blue (Sigma-Aldrich) and hematocytometer cell counter. To validate this assay, CDCs at passage 4 were seeded at a density of 2,000 cells per well in 96-well plates. After 24, 48, 72, and 96 h, cell numbers were quantified using a Live/Dead ${ }^{\circledR}$ Viability/Cytotoxicity kit (Molecular Probes) according to manufacturer's instructions. In this assay, live and dead cells were distinguished by a two-color fluorescence with live cells stained with Calcein-AM (green) and dead cells with EthD-1 (red). Two-color signals were read using a spectrophotometer at $486 \mathrm{~nm}$ and $635 \mathrm{~nm}$, respectively.

\section{Cytotoxicity of PHDIs}

This was the first study using PHDI treatment in CDC culture; thus, a careful cytotoxicity test across a gradient of PHDI drug concentrations and treatment periods was carried out to determine an optimal, sublethal PHDI treatment for CDCs. In-house synthesized DMOG powder was weighed and added to $\mathrm{CEM}$ to give final concentrations ranging from $0.1 \mathrm{mM}$ to $2 \mathrm{mM}$, based on concentrations used previously (23). In-house synthesized BIC was dissolved in dimethyl sulfoxide (DMSO) (Sigma-Aldrich) as previously described $(45,66)$ to make stock solution at a concentration of 100 $\mathrm{mM}$. Stock solution was further diluted in CEM to give final concentrations ranging from $10 \mu \mathrm{M}$ to $100 \mu \mathrm{M}$ based on concentrations used previously (29). CDCs were seeded at a density of 2,000 cells per well in 96-well plates. From day 1 to day 4, every $24 \mathrm{~h}$, cell numbers were determined by measuring the proportion of dead cells using a Live/Dead ${ }^{\circledR}$ Viability/Cytotoxicity kit (Molecular Probes) according to manufacturer's instructions. For subsequent PHDI experiments, CDCs were treated with $1 \mathrm{mM}$ DMOG and $30 \mu \mathrm{M}$ BIC for $24 \mathrm{~h}$ under normoxia $\left(21 \% \mathrm{O}_{2}\right)$. Proliferation of CDCs treated with drugs at these concentrations was measured over 4 days as above.

\section{Cardiomyocyte Differentiation}

Cardiomyocyte differentiation was induced using cardiomyocyte differentiation medium [CDM; $2 \%$ FBS ESQ (embryonic stem cell qualified) (Invitrogen), 1\% insulin transferring selenium in IMDM: DMEM/F12; 1:1 (SigmaAldrich)] supplemented with $1 \mathrm{mM}$ DMSO. The DMSOsupplemented CDM was changed every 2 days for 6 days. Cells were washed with PBS (Invitrogen) to remove the dead cells, and $2 \mathrm{ml} \mathrm{CDM}$ supplemented with $0.1 \mathrm{mM}$ ascorbic acid (Sigma-Aldrich) was added to the plate. The medium was changed every 2 days for the following 6 days (hereafter, the cells treated under such conditions are labeled as "DMSO-treated cells" for simplicity). After that, the cells were fixed with paraformaldehyde (SigmaAldrich) and immunostained with antibodies against $\alpha$-sarcomeric actin $(1: 1,000 ;$ Abcam), cardiac troponin $\mathrm{T}$ (1:1,000; Abcam), or lysed for harvesting of protein and RNA. Negative control cells were treated with CEM for 12 days, with the medium changed every 2 days.

\section{Primer Design}

Primer pairs were designed using Primer3 software based on interpretation of GenBank or Ensembl Genome Browser or were selected from published sequences (47). Primer 
specificity was enhanced by designing a primer pair that flanked the exon-exon border of the gene of interest. Primer pairs of specific cardiac stem cell markers (c-Kit), pluripotent stem cell markers (Oct-4, Klf-4, Sox 2, and Nanog), cardiac differentiation transcription factors ( $\mathrm{Nkx} 2.5$ and GATA 4), matured cardiomyocyte markers [troponin $\mathrm{T}$ (Tnnt) and myosin heavy chain $(\mathrm{MyCH})]$, and mesenchymal stem cell markers (CD90 and CD105) were used for CDC characterization, while primer pairs of target gene, such as HIF-1 $\alpha$, vascular endothelial growth factor (VEGF), erythropoietin (EPO), telomerase reverse transcriptase (TERT), and C-X-C chemokine receptor type 4 (CXCR-4), were used to investigate the effects of hypoxia on CDC culture. The sequences for primers are shown in Table 1.

\section{Quantitative (Real-Time) Reverse Transcriptase PCR ( $q R T-P C R)$}

Total RNA was extracted from cultured cells using the TRIzol reagent (Sigma-Aldrich) according to the manufacturer's instructions and treated with Turbo DNA-free (Ambion) to degrade any DNA present. Complementary DNA (cDNA) was synthesized from the RNA template using the $\mathrm{AB}$ high-capacity transcriptase kit (Applied Biosystem). Real-time PCR amplification was performed using the Applied Biosystems StepOnePlus Real-Time PCR System (AB International, CA, USA). After amplification, a melting curve was acquired by heating the product at $4^{\circ} \mathrm{C} / \mathrm{s}$ to $95^{\circ} \mathrm{C}$, cooling it at $4^{\circ} \mathrm{C} / \mathrm{s}$ to $70^{\circ} \mathrm{C}$, keeping it at $70^{\circ} \mathrm{C}$ for $20 \mathrm{~s}$, and then slowly heating it at $4^{\circ} \mathrm{C} / \mathrm{s}$ to $95^{\circ} \mathrm{C}$ to determine the specificity of PCR products. All qRTPCR data were normalized to glyceraldehyde 3-phosphate dehydrogenase (GAPDH) and $\beta$-actin (Actb) as the reference genes, as previously described (63).

\section{Western Blotting}

A total of $50 \mu \mathrm{g}$ of protein was extracted from normoxic, hypoxic, and PHDI-treated CDCs using lysis buffer containing protease inhibitors (Sigma-Aldrich), and subjected to immunoblot assay with anti-HIF-1 $\alpha$ (1:1,000; Novus), anti-citrate synthase (1:1,000; Alpha Diagnostic) and antiGLUT-1 (1:1,000; Abcam), as previously described (24). Protein loading and transfer were confirmed by Ponceau $\mathrm{S}$ staining (Sigma-Aldrich), and protein levels were normalized to internal standard (rat heart lysates) to ensure homogeneity between samples and gels. Bands were quantified using UN-SCAN-IT gel software (Silk Scientific), and all samples were run in duplicate on separate gels to confirm results.

\section{Enzyme-Linked Immunosorbent Assay (ELISA) for VEGF}

Cell culture medium was collected after the experiment, and the protein concentration of the medium was determined using a BCA protein assay kit (Thermo Scientific). A 96-well plate was coated with $100 \mu \mathrm{l} /$ well VEGF capture antibody (R\&D System) overnight. An ELISA assay was performed according to the manufacturer's instructions. The secreted VEGF protein levels were normalized to total extracellular protein.

\section{Immunocytochemistry}

Conditioned CDCs were grown on Nunc Lab-Tek ${ }^{\circledR}$ fourwell chamber slides precoated with $10 \mu \mathrm{g} / \mathrm{ml}$ fibronectin and fixed with 4\% paraformaldehyde (Sigma-Aldrich) for 10 min on ice. Fixed cells were blocked with $10 \%$ donkey serum (Biosera) in $0.1 \%$ PBS-Tween [0.9\% NaCl, $10 \mathrm{mM}$ Tris base, and $0.05 \%$ Tween (all Sigma-Aldrich)] for $1 \mathrm{~h}$ at

Table 1. List of Primer Sequences

\begin{tabular}{llll}
\hline No. & Primer & \multicolumn{1}{c}{ Forward Primer 5' to $3^{\prime}$} & \multicolumn{1}{c}{${\text { Reverse Primer } 3^{\prime} \text { to } 5^{\prime}}^{\prime}$} \\
\hline 1 & Oct-4 & GAGGGATGTGGTCGAGTGT & CCAGAGCAGTGACAGGAACA \\
2 & Sox 2 & CACAACTCGGAGATCAGCAA & CTCCGGGAAGCGTGTACTTA \\
3 & Klf-4 & CCACAGACCTGGAAAGTGGT & GGAAGACGAGGATGAAGCTG \\
4 & Nanog & TACCTCAGCCTCCAGCAGAT & AGGCCGTTGCTAGTCTTCAA \\
5 & c-Kit & AATCCGACAACCAAAGCAAC & TGACATCAGAGTTGGACACCA \\
6 & CXCR-4 & GCTACCTTGCCATTGTCCAC & ACATCGGCGAAGATGATGTC \\
7 & Nkx 2.5 & CATTTTATCCGCGAGCCTAC & GTCTGTCTCGGCTTTGCCA \\
8 & GATA 4 & CAGTCCTGCACAGCCTACCT & CCGCAGTTGACACACTCTCT \\
9 & Tnnt 2 & CGTATTCGCAATGAACGAGA & CTGTTCTCCTCCTCCTCACG \\
10 & MyHC & TATGAGACGGACGCCATACA & CTCCAGAGAGGAGCACTTGG \\
11 & CD90 & CAGAATCCCACAAGCTCCAA & GCCAGGAAGTGTTTGAACC \\
12 & CD105 & GGTACAGTGCATCGACATGG & GCTGGCCTAGCTCTATGGTG \\
13 & HIF-1 $\alpha$ & GGTGGATATGTCTGGGTTGAG & TTCAACTGGTTTGAGGACAGA \\
14 & EPO & CCAGCCACCAGAGAGTCTTC & TGTGAGTGTTCGGAGTGGAG \\
15 & VEGF- $\alpha$ & AATGATGAAGCCCTGGAGTG & ATGCTGCAGGAAGCTCATCT \\
16 & TERT & AGTGGTGAACTTCCCTGTGG & CAACCGCAAGACTGACAAGA \\
17 & GAPDH & GGGTGTGAACCACGAGAAAT & ACTGTGGTCATGAGCCCTTC \\
18 & Actb & CTAAGGCCAACCGTGAAAAG & AACACAGCCTGGATGGCTAC \\
\hline
\end{tabular}


room temperature and then incubated overnight, at $4^{\circ} \mathrm{C}$ in a humidified chamber, with the primary antibodies anti-cardiac troponin I (cTnI) (1:1,000; Abcam), anti- $\alpha$-sarcomeric actin $(1: 1,000 ;$ Abcam), anti-myosin heavy chain $(1: 1,000$; Abcam), anti-c-Kit (1:1,000; Santa Cruz), anti-CD90 (1: 1,000; BD Pharmingen) anti-Oct-4 (1:1,000; Santa Cruz), anti-Klf-4 (1:1,000; Abcam), anti-Nanog (1:1,000; Abcam), or anti-Sox $2(1: 1,000$; Santa Cruz) diluted in PBS in the ratio 1:100. Cells were then incubated with the appropriate secondary antibody conjugated to FITC and the immunofluorescence detected using a confocal microscope (Zeiss Confocal LSM 700). For confocal cytometry, the number of positive cells for each protein was counted in 10 representative fields.

\section{Measurement of Cell Respiration}

Cell oxygen consumption rates were measured using a Clark-type oxygen electrode (Strathekelvin Instruments, Scotland) as previously described (48). Two million cells were suspended in $500 \mu \mathrm{l}$ respiratory medium $[100 \mathrm{mM}$ $\mathrm{KCl}, 50 \mathrm{mM}$ MOPS, $1 \mathrm{mM}$ EGTA, $5 \mathrm{mM} \mathrm{KH} \mathrm{PO}_{4}$, and $1 \mathrm{mg} / \mathrm{ml} \mathrm{BSA} \mathrm{(all} \mathrm{Sigma-Aldrich),} \mathrm{pH}$ 7.4] and incubated in a stirred chamber at $30^{\circ} \mathrm{C}$. Respiration was measured under basal unstimulated conditions for $5 \mathrm{~min}$, followed by addition of $10 \mathrm{mM}$ pyruvate and $5 \mathrm{mM}$ malate, $2 \mathrm{mM}$ oligomycin, and $10 \mathrm{mM}$ carbonyl cyanide p-(trifluoromethoxy) phenylhydrazone (FCCP) (all Sigma-Aldrich). Cell oxygen consumption rates in each solution were traced and recorded. Traces were then analyzed using Strathekelvin 782 Oxygen System v3.0 software.

\section{Cell Metabolism}

Glucose and lactate levels in cell culture medium were determined using an ABX Pentra 400 Chemistry Analyzer (glucose reagent A11A01668 and lactate reagent A11A01721; Horiba Ltd., USA).

\section{Statistical Analysis}

Data obtained were expressed as mean \pm standard error of the mean (SEM). All statistical analyses were performed using Excel, Prism, or SPSS software. The statistical differences of measurements made in cells from the same animals were analyzed using a paired $t$-test, whereas multiple comparisons between groups were analyzed using a one-way analysis of variance (ANOVA). Repeated-measures ANOVA was performed to compare curves. A Tukey post hoc test was used to analyze statistical difference between groups or curves. A value of $p<0.05$ was considered statistically significant.

\section{RESULTS}

\section{Effects of In Vitro Multiple Passaging on CDC}

In vitro propagation of cardiac stem cells from EDCs up to passage 10 (P10) CDCs under normoxia showed a gradual decrease in expression of $\mathrm{mRNA}$ for the telomere reverse transcriptase (TERT) enzyme and the cardiac stem cell marker, c-Kit (Fig. 1A, B).

\section{Hypoxia Increased Cell Proliferation Rate}

Atrial explants were cultured under normoxia (21\% $\left.\mathrm{O}_{2}\right)$ or hypoxia $\left(2 \% \mathrm{O}_{2}\right)$. Within 3 to 6 days in both normoxic and hypoxic cultures, fibroblast-like cells started to migrate away from the edge of the explants. Generally, under both normoxia and hypoxia, EDCs became confluent and were ready for harvesting within 9 days of plating (Fig. 2A). After 9 days in culture under hypoxia, $10.3 \pm 0.3 \times 10^{5}$ EDCs were produced from $0.1 \mathrm{~g}$ explant tissue, 1.4-fold more than those generated under normoxia $\left(7.3 \pm 1 \times 10^{5} \mathrm{EDC} / 0.1 \mathrm{~g}\right)$. These rates were maintained up to day 18 , with $22 \pm 1 \times 10^{5} \mathrm{EDCs} / 0.1 \mathrm{~g}$ generated by hypoxic culture and $18 \pm 1 \times 10^{5} \mathrm{EDCs} / 0.1 \mathrm{~g}$ generated by normoxic culture (Fig. 2B). EDCs aggregated to form cardiospheres after 2 days in culture. Approximately 400 cardiospheres were obtained from each well after 4 days of incubation under normoxia or hypoxia (Fig. 2C), with hypoxic cardiospheres forming larger cell clusters $\left(0.033 \pm 0.004 \mathrm{~mm}^{2}\right)$ compared with those under normoxia $\left(0.017 \pm 0.002 \mathrm{~mm}^{2}\right)$ (Fig. 2D). Isolated cardiospheres were replated on fibronectin and formed CDCs after 3-4 days of incubation. Hypoxic culture yielded higher cell numbers than normoxia at day 5 of each passage from P1 until P5 (Fig. 2E). On average, 5.2 \pm 0.3 -fold expansion was observed at each passage for hypoxic cells, whereas normoxic CDCs maintained a 3.0 \pm 0.1 -fold increase during each passage. To further validate the cell proliferation data, cell numbers at P4 were quantified using Live/ Dead $^{\circledR}$ Viability/Cytotoxicity assay every $24 \mathrm{~h}$ for 4 days. The number of hypoxic cells was significantly higher than that of normoxic cells after $48 \mathrm{~h}$, and this increase was maintained up to $96 \mathrm{~h}$ in culture (Fig. 2F).

Taken together, approximately $6 \times 10^{6} \mathrm{P} 2 \mathrm{CDCs}$ were obtained from hypoxic explants within 21 days, a week (or $25 \%$ ) faster than the same number from normoxic explants.

\section{Hypoxic CDCs Expressed HIF-1 $\alpha$ and HIF-1 $\alpha$-Regulated Genes}

CDCs cultured under hypoxia expressed significantly higher HIF- $1 \alpha$ mRNA (2.9 \pm 0.6 -fold), compared with normoxic CDCs (Fig. 3A). In line with this, HIF-1 $\alpha$ protein levels were 3.7 \pm 0.5 -fold higher in hypoxic CDCs, compared with normoxic CDCs (Fig. 3A). Activation of HIF- $1 \alpha$ under hypoxia subsequently upregulated several important genes that are known to be HIF regulated, including VEGF (3.5 \pm 0.6 -fold), EPO (3.3 \pm 0.9 -fold), CXCR-4 (6.7 \pm 1.0$)$, and TERT (2.7 \pm 0.4 -fold) (Fig. 3A). Elevated VEGF protein levels were confirmed using ELISA (Fig. 3A). 

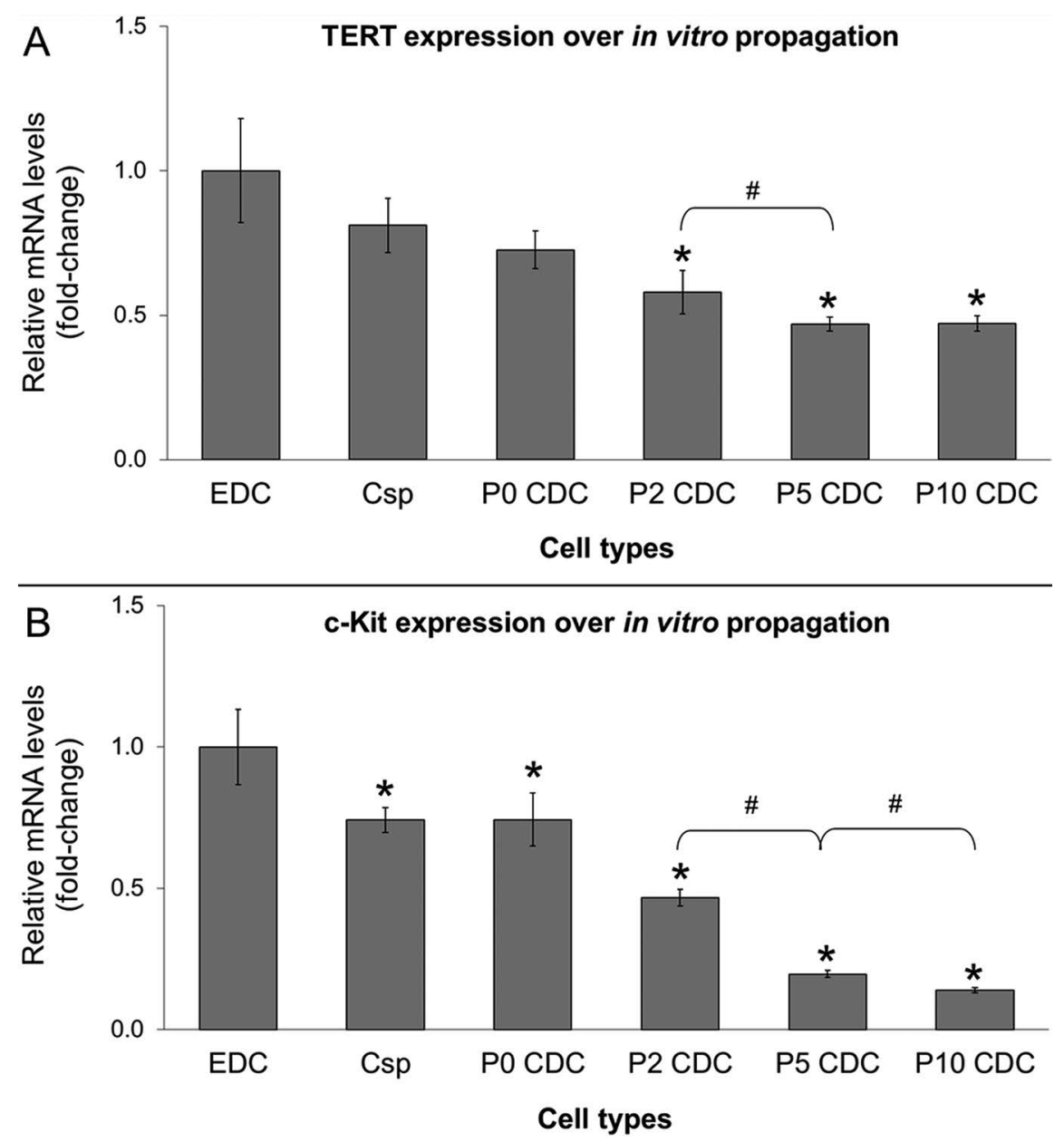

Figure 1. In vitro propagation of cardiac stem cells from EDCs up to passage 10 (P10) CDCs showed a gradual decrease in (A) TERT and (B) c-Kit mRNA expression levels. mRNA expression of all cell types were normalized to the geometric mean of GADPH and Actb (housekeeping genes) and EDC (calibrator) $(n=3)(* p<0.05$ vs. EDC; $\# p<0.05$ between the two groups indicated).

\section{Hypoxia Increased Cardiac Stem Cell Markers in the CDC Population}

Under hypoxia, CDCs showed significantly increased mRNA expression for c-Kit (2.3 \pm 0.1 -fold) and the pluripotent markers, Oct-4 (2.9 \pm 0.5 -fold), Klf-4 (3.1 \pm 0.6 -fold), Sox 2 (5.4 \pm 1.5 -fold), and Nanog (4.5 \pm 1.1 -fold) and with reduced expression of mesenchymal markers CD90 and CD105 (32\% and 65\%, respectively) (Fig. 3A). Changes in mRNA expression were reflected in the protein expression levels; we found increased protein expression of c-Kit (3.1 \pm 0.3 -fold) and of the pluripotent markers, Oct-4 (1.5 \pm 0.1 -fold), Klf-4 (2.7 \pm 0.5 -fold), Nanog $(4.1 \pm 0.2$ fold), and Sox 2 (3.2 \pm 0.2 -fold), in hypoxic CDCs, compared with normoxic CDCs, with a significant decrease in CD90 protein expression by 56\% (Fig. 3A, B). On the other hand, the mRNA expression of cardiac transcription factors, Nkx 2.5 and GATA 4, and the mature cardiomyocyte markers Tnnt and MyHC was not significantly different after hypoxic culture (Fig. 3A).

\section{Cardiomyocyte Differentiation of Hypoxic CDCs}

Under normoxia $\left(21 \% \mathrm{O}_{2}\right)$, hypoxic-preconditioned CDCs treated with DMSO showed significantly increased Tnnt mRNA expression by $3.0 \pm 1.0$-fold, compared with nontreated hypoxic CDCs (Fig. 4A). However, it was found that the level of Tnnt in DMSO-treated hypoxic CDCs was significantly lower than in the DMSO-treated normoxic CDCs (5.2 \pm 0.6 -fold) (Fig. 4A). These findings indicated that hypoxic-preconditioned cells retained the ability to differentiate into cardiomyocytes; however, this ability was attenuated compared with normoxic cells.

In order to investigate the effect of the hypoxic environment on CDC cardiomyogenic potential, both normoxic and hypoxic CDCs were differentiated under hypoxia $\left(2 \% \mathrm{O}_{2}\right)$. Here, the mRNA expression levels of Nkx 2.5 in both normoxic and hypoxic CDCs were not significantly increased by treatment with DMSO. Although the expression of Tnnt was increased in normoxic CDCs differentiated under hypoxia, the increase was significantly lower 


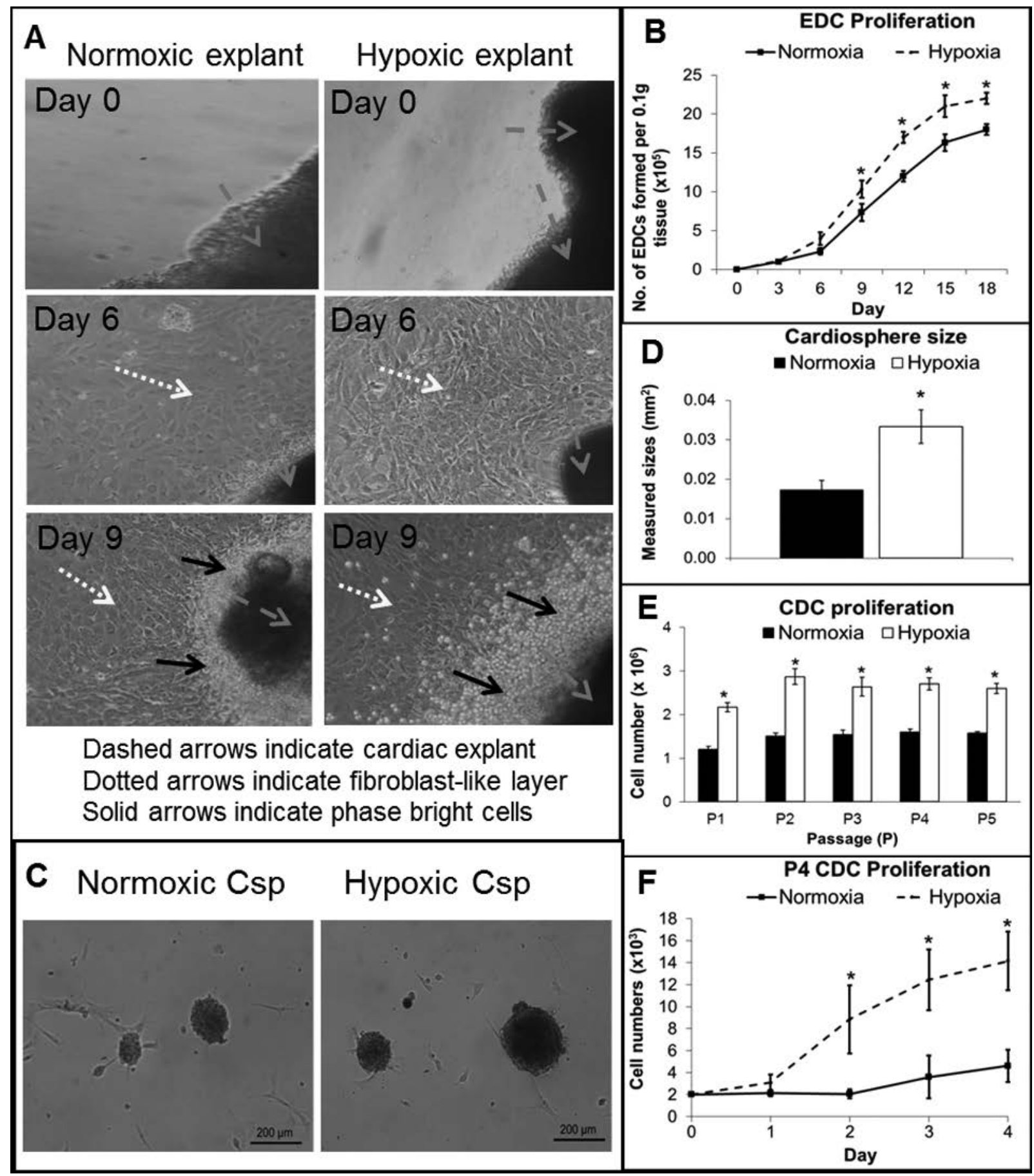

Figure 2. Effects of hypoxic preconditioning on EDC proliferation rate, cardiosphere size, CDC proliferation rate. (A) Atrial heart tissue $(n=4)$ was separated into two equal portions and cultured under normoxia or hypoxia for up to 18 days. At day 0 , the black clump shown at the corner (indicated by dashed arrows) was an edge of a freshly plated cardiac tissue explant. At day 6, fibroblast-like cells (indicated by dotted arrows) were found migrating away from the edge of the explants. At day 9, phase bright cells (indicated by solid arrows) were found to grow on top of this fibroblast-like monolayer. All these cells were collectively termed as explant-derived cells (EDCs). (B) EDCs generated under normoxia or hypoxia were harvested, and cell numbers were counted. At day 9, hypoxic explants generated approximately 1.4-fold more EDCs, compared with normoxic explants, and this rate was maintained up to 18 days. (C) Morphology of normoxic and hypoxic cardiospheres (Csp) were significantly different, with (D) hypoxic Csp 1.9-fold larger than the normoxic Csp. (E) Hypoxia also yielded higher cardiosphere-derived cell (CDC) numbers than normoxia at day 5 of each passage from P1 until P5 (* $p<0.05$ vs. normoxia). (F) CDC proliferation assay was validated using Live/Dead ${ }^{\circledR}$ Viability/Cytotoxicity kit (Molecular Probes). Hypoxic CDCs at P4 showed higher proliferation than normoxic P4 CDCs after 2 days in culture ( $* p<0.05$ vs. normoxia). 


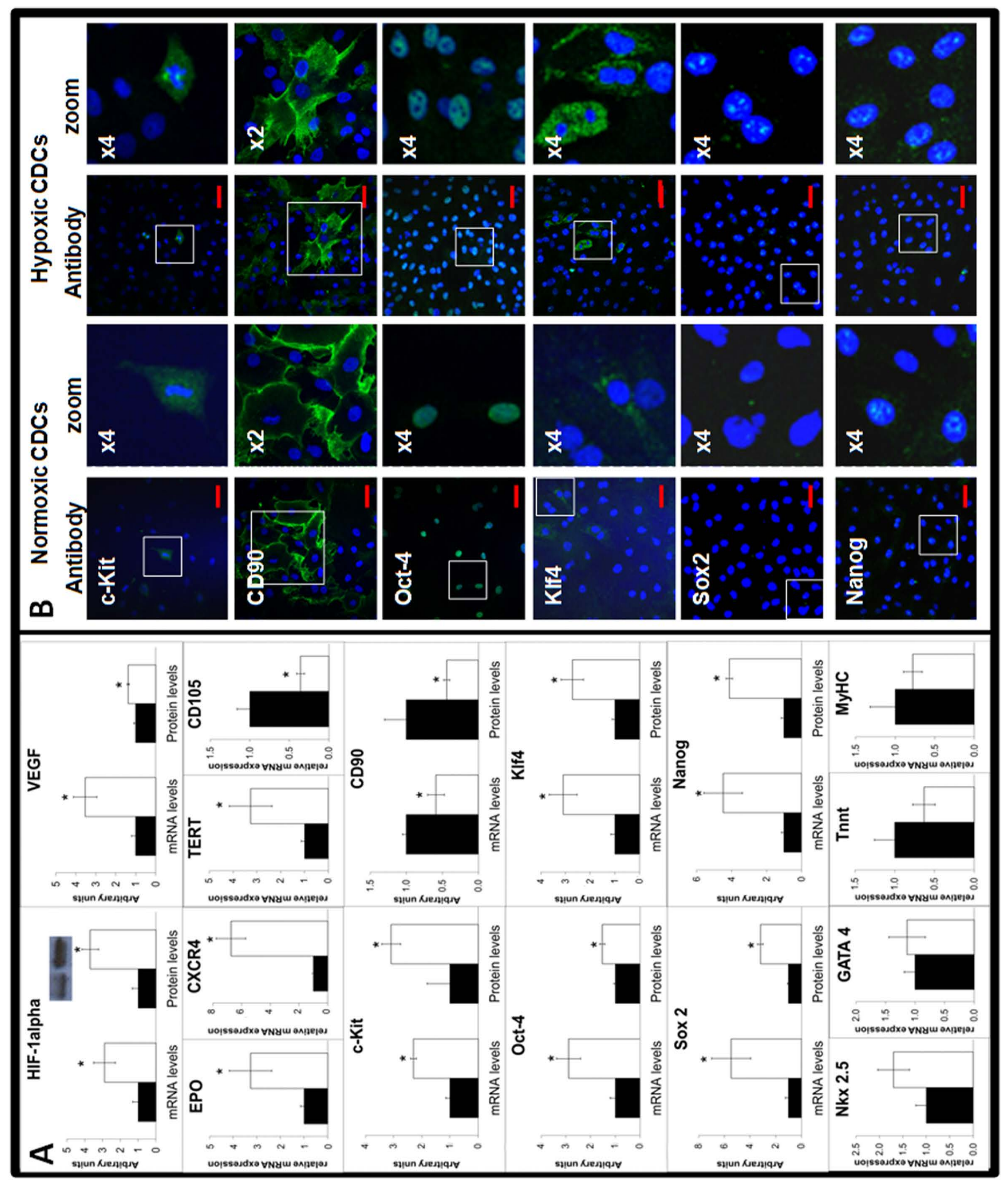


than that of the same cells differentiated under normoxia (2.1 \pm 0.3 -fold vs. 5.2 \pm 0.6 -fold for hypoxic vs. normoxic environment), indicating that the potential for differentiation is partially attenuated under hypoxia (Fig. 4A).

CDCs in culture can differentiate spontaneously, particularly when proliferating slowly, and show expression of cardiac proteins including $\alpha$-sarcomeric actin, myosin heavy chain, and troponin T (Fig. 4B, control normoxic, and Fig. 4C, hypoxic CDCs). Differentiation can be stimulated further by treatment with DMSO. Immunostaining on CDCs cultured for 2 weeks showed higher expression of $\alpha$-sarcomeric actin, myosin heavy chain, and troponin $\mathrm{T}$ in those treated with DMSO (Fig. 4B, DMSO-treated normoxic, and Fig. 4C, hypoxic CDCs). Moreover, treatment with DMSO induced CDCs to change morphology, compared to nontreated CDCs.

\section{Preconditioning Adult CDCs With PHDIs}

PHDI cytotoxity was assayed by quantification of the number of dead cells in cultures treated with a range of concentration of each drug. At $24 \mathrm{~h}$, both DMOG- and BIC-treated cells at all concentrations did not increase the number of dead cells (Fig. 5A, B). Prolonged DMOG treatment (4 days) caused cytotoxicity at concentrations above $0.5 \mathrm{mM}$ (Fig. 5A), while BIC treatment at all concentrations was not toxic to the cells for up to 4 days (Fig. 5B).

Protein levels of HIF- $1 \alpha$ and the HIF-regulated glucose transporter, GLUT-1, in P2 CDCs treated with DMOG and $\mathrm{BIC}$ in gradient concentrations also were determined. We found that HIF- $1 \alpha$ activation by DMOG was time and concentration dependent, being maximal after $24 \mathrm{~h}$ at $0.5 \mathrm{mM}$ or $1 \mathrm{mM}$ DMOG but not significantly increased at the highest DMOG concentration $(2 \mathrm{mM})$ or after prolonged treatment (4 days). Similarly, GLUT-1 expression peaked at $24 \mathrm{~h}$ after treatment with $1 \mathrm{mM}$ DMOG but decreased after prolonged treatment or at higher concentrations of DMOG (Fig. 5Ci). BIC is reported to be a more specific PHDI and thus significantly upregulated both HIF-1 $\alpha$ and GLUT-1 at low concentrations $(30 \mu \mathrm{M})$ (Fig. 5Cii). Based on the negative cytotoxicity and the optimal HIF- $1 \alpha$ and GLUT-1 expression, treatment with $1 \mathrm{mM}$ DMOG or $30 \mu \mathrm{M}$ BIC for $24 \mathrm{~h}$ was determined as the optimum condition for CDC culture and thus was used in the following experiments.

To validate this, cell proliferation and viability assay were assessed on CDCs exposed to $1 \mathrm{mM}$ DMOG or $30 \mu \mathrm{M}$
BIC for 24, 48, 72, and 96 h. Both PHDIs increased CDC proliferation within the first $24 \mathrm{~h}$, compared with nontreated control cells ( $p=0.07$ for DMOG, $p<0.05$ for BIC; Fig. $5 \mathrm{D})$. The toxicity of DMOG over 4 days caused a gradual decrease in cell numbers after $24 \mathrm{~h}$, and BIC-treated cells did not proliferate after $24 \mathrm{~h}$, although this may be because they had reached confluence. Thus, after 4 days, the number of drug-treated CDCs was not significantly different from that of the control cells (Fig. 5D). These data indicated 24-h treatment of $1 \mathrm{mM}$ DMOG and $30 \mu \mathrm{M}$ BIC were optimal to the cells.

\section{Effects of PHDI Preconditioning on CDC Gene Expression}

DMOG and BIC treatment increased c-Kit mRNA expression by $1.6 \pm 0.2$-fold, similarly, compared with nontreated normoxic CDCs (Fig. 6A). CD90 mRNA levels were significantly reduced after treatment with each PHDI, compared with normoxic cells (Fig. 6A). Unlike culture under hypoxia, treatment with PHDIs did not increase mRNA levels of Oct-4, Klf-4, Sox 2, and Nanog (data not shown) nor decrease the expression of CD105 (Fig. 6A).

DMOG significantly increased the mRNA levels of EPO, VEGF, and CXCR-4, compared with normoxic CDCs, mimicking the hypoxic-preconditioned CDCs. $\mathrm{BIC}$ treatment resulted in significantly higher EPO levels, compared both with normoxic controls and with DMOGtreated CDCs, but did not induce upregulation of VEGF mRNA (Fig. 6B).

\section{Effects of PHDI Preconditioning on \\ Cardiomyogenic Differentiation}

After induction of cardiomyogenic differentiation of PHDI-treated cells using DMSO, increased mRNA expression of Tnnt $(\mathrm{DMOG}=1.6 \pm 0.1$-fold; $\mathrm{BIC}=1.7 \pm 0.1$ fold) indicated that PHDI-treated CDCs retained the cardiomyogenic differentiation potential (Fig. 7A). However, the mRNA expression of these cardiomyocyte markers in differentiated PHDI-treated CDCs was significantly lower compared to differentiated normoxic controls (Nkx 2.5 $=6.0 \pm 0.7$-fold vs. $1.8 \pm 0.2$-fold vs. $1.5 \pm$ 0.1 -fold; Tnnt $=5.2 \pm 0.6$-fold vs. $1.6 \pm 0.1$-fold vs. $1.7 \pm$ 0.1 -fold for normoxic CDCs vs. DMOG vs. BIC, respectively) (Fig. 7A). This indicated that PHDI treatment did not elevate the cardiomyogenic potential of CDCs compared to normoxic CDCs, mimicking the effects of

\section{FACING PAGE}

Figure 3. Effects of hypoxic preconditioning on CDC mRNA and protein expression levels. (A) The relative mRNA or protein expression of HIF-1 $\alpha$, VEGF, EPO, CXCR-4, TERT, CD105, c-Kit, CD90, Oct-4, Klf-4, Sox 2, Nanog, Nkx 2.5, GATA 4, Troponin T (Tnnt), and myosin heavy chain (MyHC) for normoxic P2 CDCs (represented by black boxes) and hypoxic P2 CDCs (represented by white boxes) $(n=3)$. (B) Representative confocal images (of three independent experiments) of the immunostaining for c-Kit, CD90, Oct-4, Klf-4, Sox 2, and Nanog for normoxic P2 CDCs and hypoxic P2 CDCs. * $p<0.01$ versus normoxic P2 CDCs. Green fluorescence indicates the specific antibody while blue fluorescence indicates DAPI staining. The white boxes indicated the zoomed in area. Scale bars: $50 \mu \mathrm{m}$. 

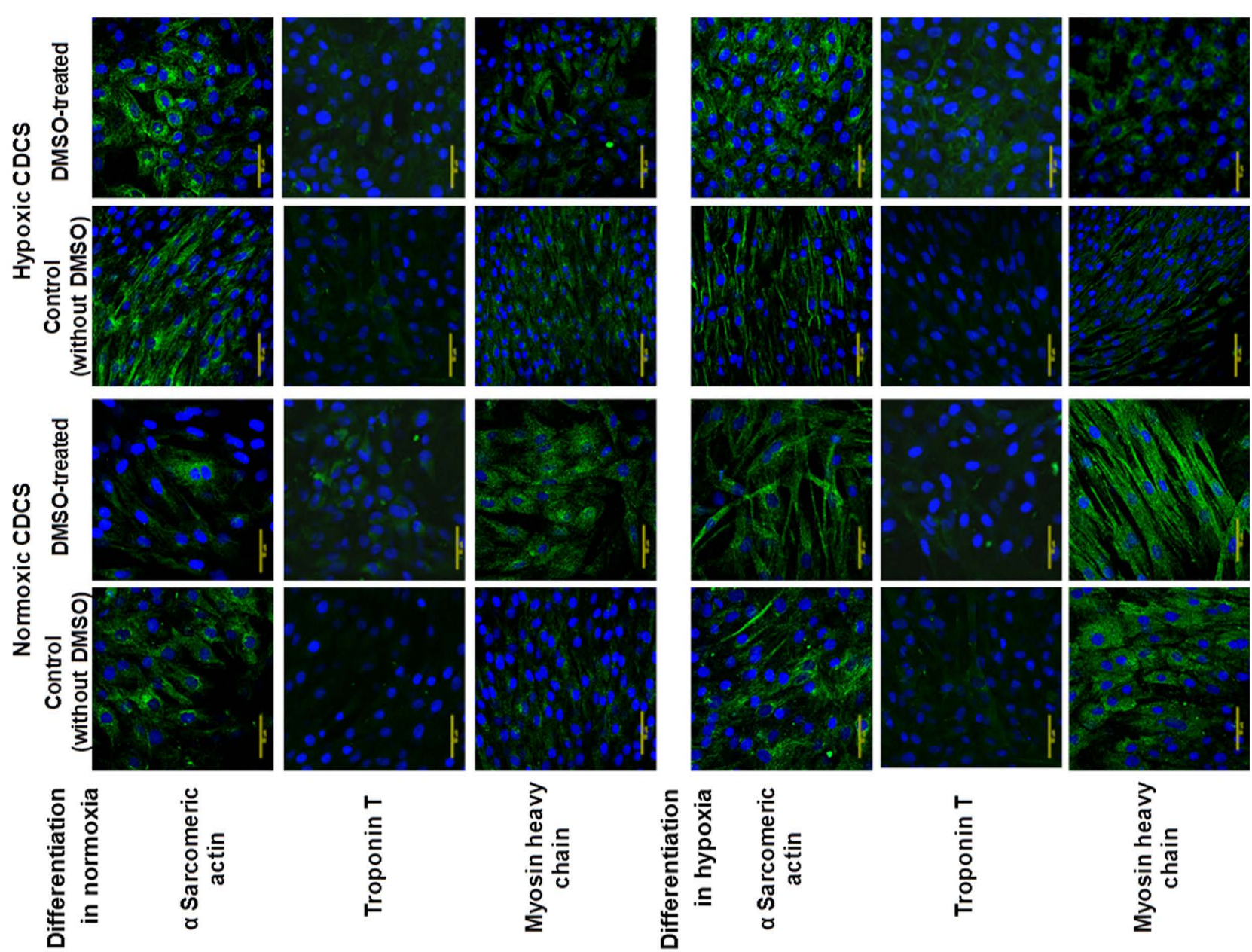

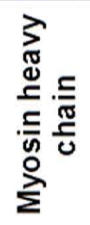
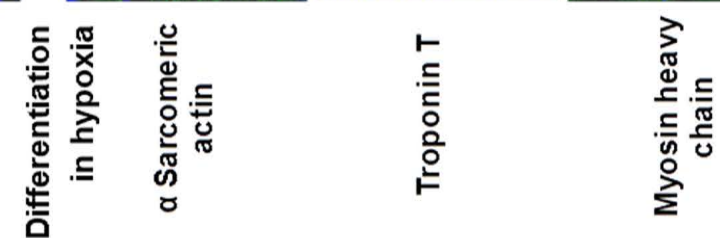

๓

0

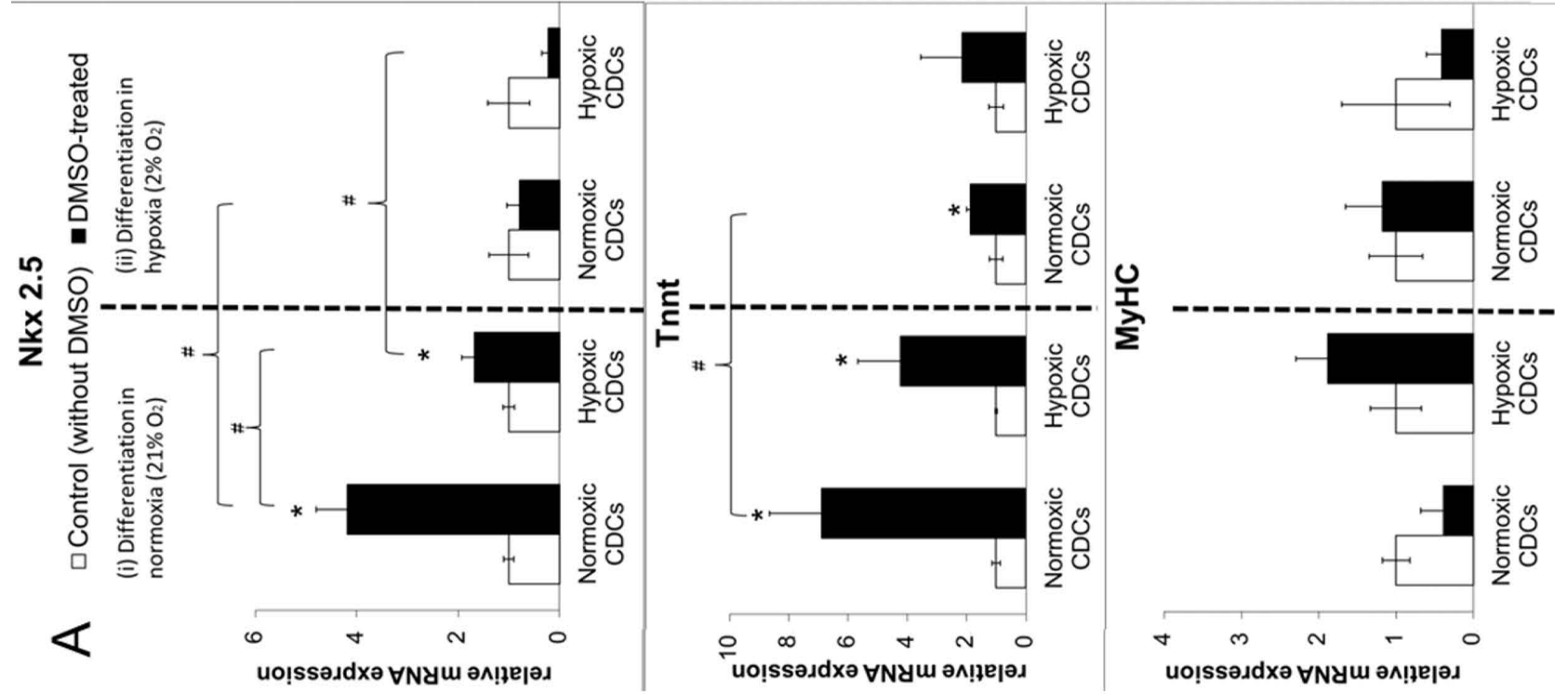


hypoxic preconditioning on CDC cardiomyogenic potential (see Fig. 4A). The mRNA expression data were confirmed using confocal immunostaining (Fig. 7B). Protein expression of sarcomeric actin and Troponin $\mathrm{T}$ were significantly increased in both DMOG- and BIC-treated CDCs after induction with DMSO, mimicking the effects of DMSO on normoxic CDCs (control).

\section{Metabolic Adaptation of Hypoxic or PHDI- Preconditioned CDCs}

Reduced Oxygen Uptake. Cellular basal respiration rates were significantly reduced by $\sim 75 \%$ under hypoxia and by $\sim 55 \%$ and $\sim 50 \%$ after treatment with DMOG or BIC for $24 \mathrm{~h}$, respectively (Fig. 8A). Respiration was then maximally stimulated by adding FCCP, an uncoupling agent that dissipates the proton gradient across the mitochondrial inner membrane (55). Although respiration rates increased in all cells after the addition of FCCP, those of hypoxic and PHDI-preconditioned cells remained significantly lower than those of normoxic cells, indicating that oxidative respiration was reduced by hypoxic culture or by pharmacological activation of HIF.

Citrate synthase protein expression was unchanged in hypoxic and PHDI-preconditioned CDCs, confirming that the reduced oxygen consumption did not result from reduced mitochrondrial density following hypoxic or PHDI preconditioning (Fig. 8B).

Increased Glucose Metabolism. The expression of GLUT-1 protein increased 7 \pm 2 -fold under hypoxia, compared with normoxia (Fig. 8C). Hypoxic CDCs utilized $0.7 \pm 0.1 \mathrm{mM}$ glucose per million cells per day, 3.3 -fold more than normoxic CDCs and produced $1.6 \pm 0.1 \mathrm{mM}$ lactate per million cells per day, 2.8-fold more than those produced under normoxia (Fig. 8D). After PHDI treatment, a significant increase was found in glucose uptake $(\mathrm{DMOG}=$ 2.1-fold; $\mathrm{BIC}=1.9$-fold) and lactate production $(\mathrm{DMOG}=$ 2.1 -fold; $\mathrm{BIC}=1.4$-fold), compared with normoxic nontreated CDCs (Fig. 8D).

These data suggest that under hypoxia, CDCs adapted to low oxygen conditions by reducing oxygen consumption, increasing the expression of GLUT-1 and switching to glycolytic metabolism, indicated by the increased glucose consumption and lactate production. This adaptation could also be induced by pharmacological inhibition of prolyl hydroxylase activity.

\section{DISCUSSION}

\section{Hypoxic Preconditioning of CDCs Enhances Their Therapeutic Potential}

Stem cells reside in niches where they maintain pluripotency and the potential for self-replication. However, during each round of DNA replication, processes that underlie replicative aging could ultimately lead to the senescence of stem cells due to the telomere shortening $(43,69)$. We found that mRNA expression of TERT deteriorated during long-term cell passaging, implying cellular aging in vitro. TERT is a reverse transcriptase that synthesizes telomere repeats on the telomere ends at the tips of chromosomes, protecting the chromosomes from deterioration and also maintaining the overall genomic stability $(5,70)$. In various types of stem cells, telomerases function to ensure long-term self-renewal capacity via maintenance of telomere length $(1,13)$. Also, it was found that in vitro cell propagation gradually decreased the expression of c-Kit. Recent studies have reported a similar reduction of c-Kit expression, in purified c-Kit cells and in CDCs over time in culture (35). Koninckx et al. demonstrated that clonogenic-derived $\mathrm{c}-\mathrm{Kit}^{+}$cells and CDCs lost c-Kit expression after several passages in culture (35), while Gambini et al. showed that c-Kit expression was significantly downregulated at the RNA level after four passages (21). Thus, in order to optimize the therapeutic potential of adult CDCs, here cells were preconditioned with low oxygen or with the hypoxic mimetics: DMOG and BIC.

Enhanced cell proliferation rates were found for EDCs and CDCs under hypoxia, compared with under normoxia. Also, hypoxic EDCs formed larger cardiospheres, compared with normoxic EDCs, which most likely resulted from rapid proliferation of cardiac stem cells in the core of the sphere as suggested by Li et al. (40). Hypoxic preconditioning also successfully increased the expression of c-Kit. The CDC population in culture contained only a minority of c-Kit ${ }^{+}$cells, as has been shown by others (35), but nevertheless CDCs have been shown to have beneficial effect in the clinic (44). Despite the current

FACING PAGE

Figure 4. Cardiomyocyte differentiation of normoxic and hypoxic P2 CDCs. (A) The relative mRNA expression of Nkx 2.5, Tnnt, and $\mathrm{MyHC}$ for normoxic and hypoxic P2 CDCs after treatment with DMSO for 2 weeks under (i) normoxia (left panel) or (ii) hypoxia (right panel) conditions $(n=3)$. mRNA expression of hypoxic cells was normalized to the geometric mean of GAPDH and Actb (housekeeping genes) and nontreated control cells (calibrator). ${ }^{*} p<0.05$ versus nontreated control. \# $p<0.05$ between the two groups linked with arrow. (B, C) Representative confocal images (of three independent experiments) of the DMSO differentiation protocol in normoxia (B) and hypoxia (C). An equal number of cells $\left(8 \times 10^{5}\right.$ per chamber) of each condition were trypsinized and seeded on four-well chamber slides coated with fibronectin $(10 \mu \mathrm{g} / \mathrm{ml})$ and stained with DAPI and $\alpha$-sarcomeric actin, troponin T, or myosin heavy chain. Left panel: normoxic CDCs (control or treated with DMSO), right panel: hypoxic CDCs (control or treated with DMSO). Scale bars: $50 \mu \mathrm{m}$. 


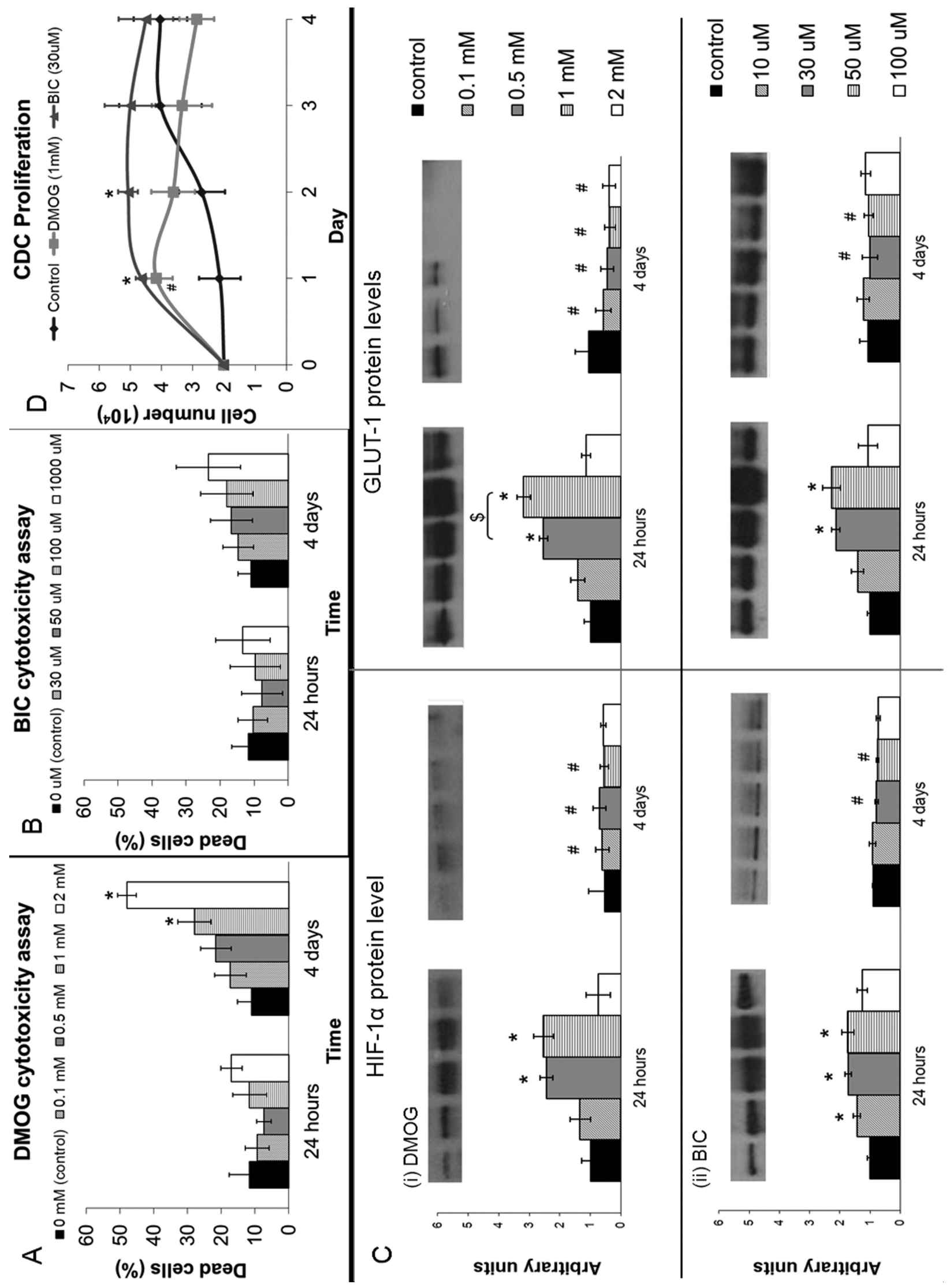



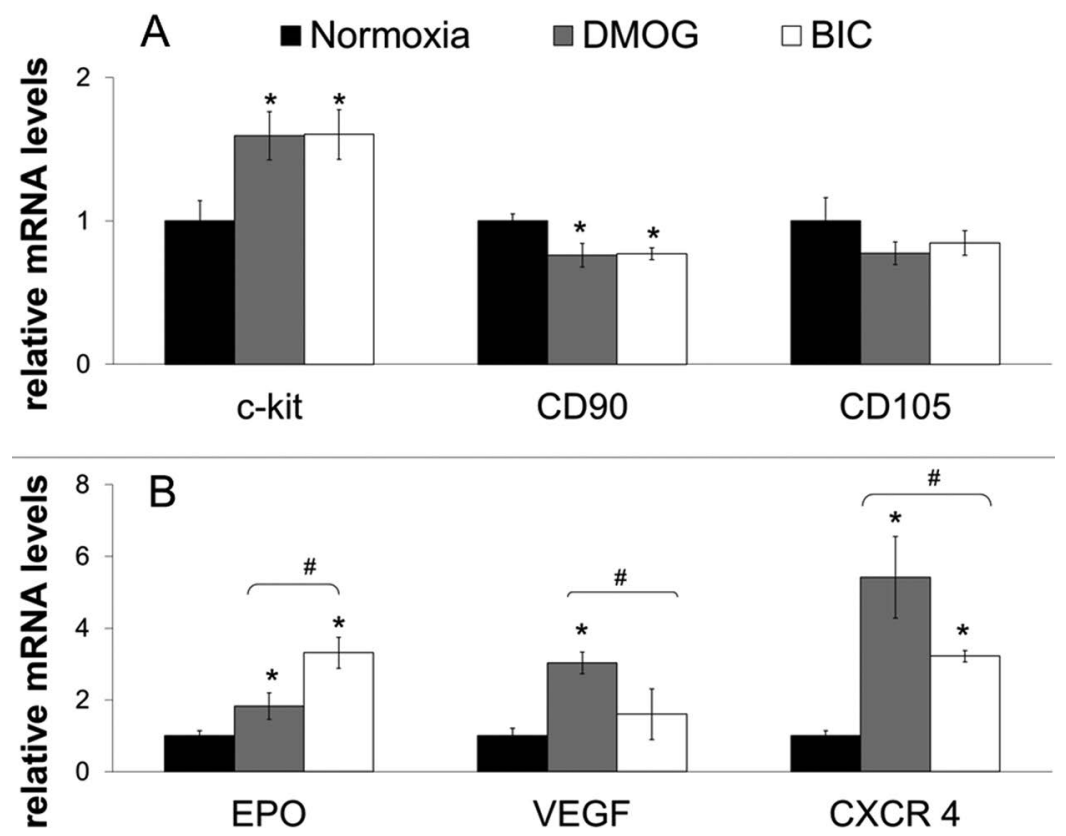

Figure 6. Effects of PHDI preconditioning on CDC mRNA expression. Relative mRNA expression of c-Kit, CD90, CD105, EPO, VEGF, and CXCR-4 in nontreated P2 CDCs (control) and CDCs treated with $1 \mathrm{mM}$ DMOG and $30 \mu \mathrm{M}$ BIC for $24 \mathrm{~h}(n=4)$, normalized to the geometric mean of GAPDH and Actb (housekeeping genes) and nontreated control cells (calibrator). ${ }^{*} p<0.05$ versus control. $\# p<0.05$ between two groups indicated.

controversy as to whether endogenous c-Kit cells are involved in cardiac repair, or their contribution to cardiac regeneration is minimal (67), cardiac cells expressing c-Kit have been shown to be clonogenic and to be capable of differentiating into beating cardiomyocytes (59), sufficient for cardiac regeneration and repair (17), and therefore the expression of c-Kit in populations of progenitor cells remains of interest. Additionally, hypoxic preconditioned CDCs showed reduced mesenchymal markers, CD90 and CD105. Cheng et al. reported that CD90 expression negatively correlates with the therapeutic benefits of CDCs in human (9); therefore, we postulate that hypoxic preconditioned CDCs with lower CD90+ cell subpopulation may promote overall benefit of CDC therapy. Proliferating hypoxic cells also maintained expression of pluripotent factors Oct-4, Klf-4, Sox 2, and Nanog, with decreased expression of mature cardiac genes, in agreement with others $(14,18,31)$. Furthermore, we found that the TERT mRNA level was upregulated under hypoxia. Maintenance of CDCs in the pluripotent state before in vivo transplantation is important to prevent the cells from losing their proliferation ability, karyotype stability, and developmental potential.

In addition, we found that hypoxia attenuated cardiomyogenic differentiation in vitro, compared to the normoxic cells. Although the expression of cardiomyocyte genes was attenuated under hypoxia, which would affect their differentiation potential into new cardiomyocytes in vivo, this attenuation was partial, as we found significantly increased expression of Nkx 2.5 and Tnnt (cardiomyocyte genes) in hypoxic-preconditioned CDCs treated with DMSO, compared with hypoxic CDCs without DMSO treatment, indicating that hypoxic-preconditioned CDCs were still able to differentiate into cardiomyocytes, however, at a slower rate. Low oxygen levels are detrimental to the survival of mature cardiomyocytes, due in part to increased acidosis and the release of reactive oxygen species (6), and thus protective mechanisms may inhibit progenitor cell differentiation. More work is required to fully investigate this inhibition, as therapeutically the

FACING PAGE

Figure 5. Preconditioning adult CDCs with PHDIs. P2 CDCs at $70 \%$ to $80 \%$ confluency were treated with (A) DMOG and (B) BIC at varying concentrations $(n=4)$. The percentage of dead cells was determined after $24 \mathrm{~h}$ and 4 days of treatment. $* p<0.05$ versus nontreated control. (C) Western blot analysis of HIF-1 $\alpha$ (left panel) and GLUT-1 (right panel) protein levels in $70 \%$ to $80 \%$ confluent P2 CDCs treated with (i) DMOG and (ii) BIC with a range of concentrations for $24 \mathrm{~h}$ or 4 days $(n=3)$. Protein levels were expressed in arbitrary units relative to cells treated with control at $24 \mathrm{~h}$. $* p<0.05$ versus control at $24 \mathrm{~h} ; \# p<0.05$ versus corresponding concentration at $24 \mathrm{~h}$; $\$ p<0.05$ between the two groups linked with arrow. (D) PHDI-treated CDC proliferation over 4 days of treatment with $1 \mathrm{mM} \mathrm{DMOG}$ and $30 \mu \mathrm{M}$ BIC $(n=4)$. Both PHDIs increased cell proliferation for the initial $24 \mathrm{~h}(p=0.07$ for DMOG, $p<0.05$ for BIC nontreated control). 

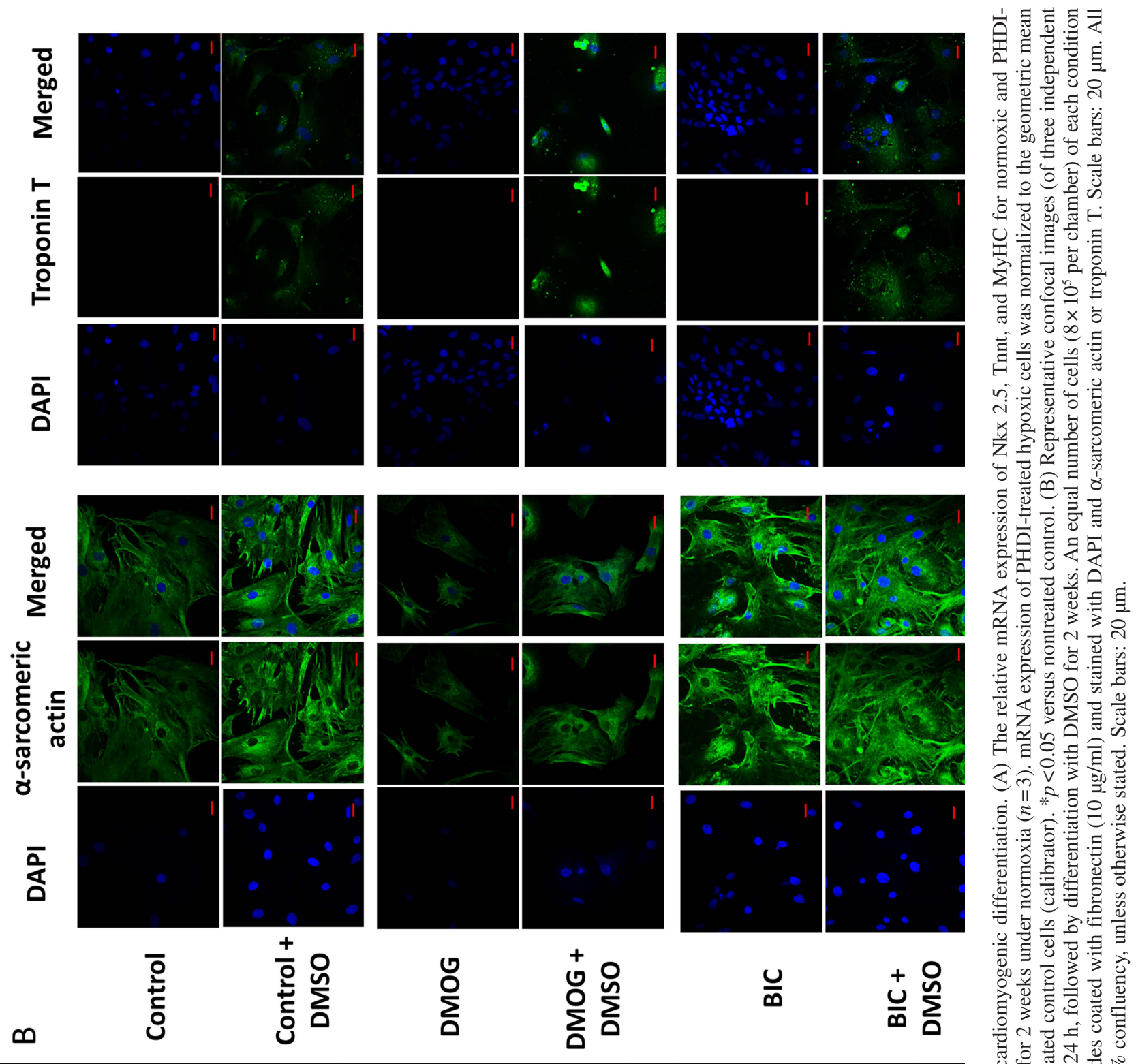

후의

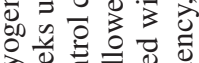

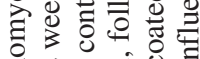

워워

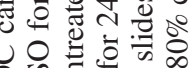

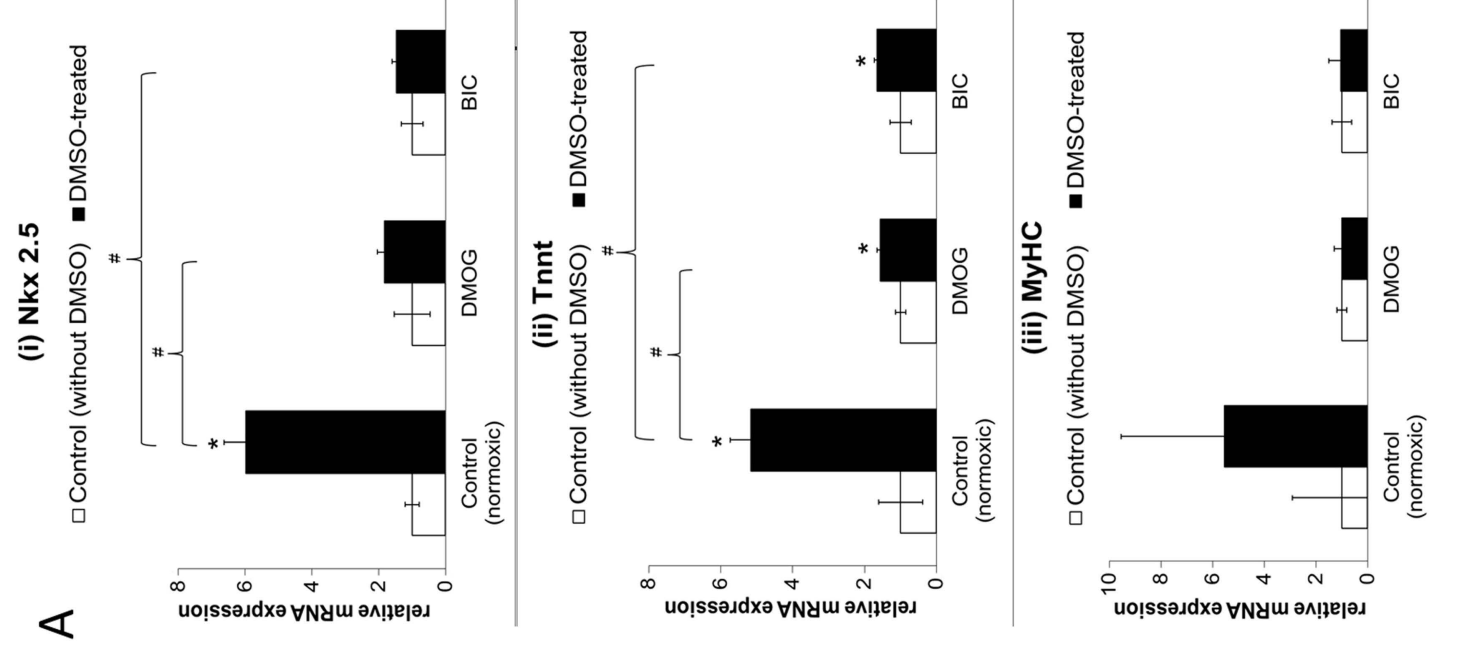

Uิ

。

on. 在

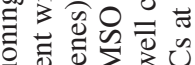

氙兽 ${ }_{00}^{\infty}$

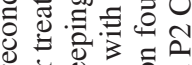

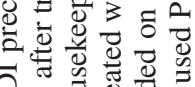

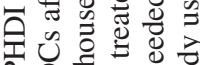

记

능 응

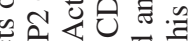

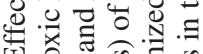

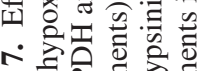

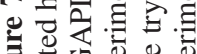

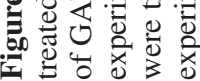




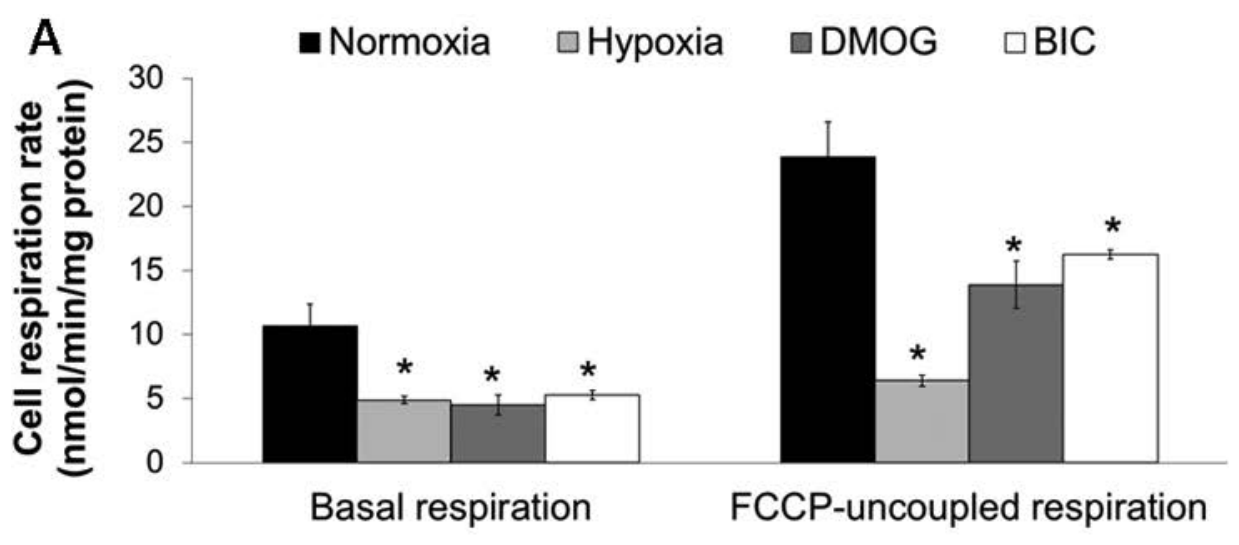

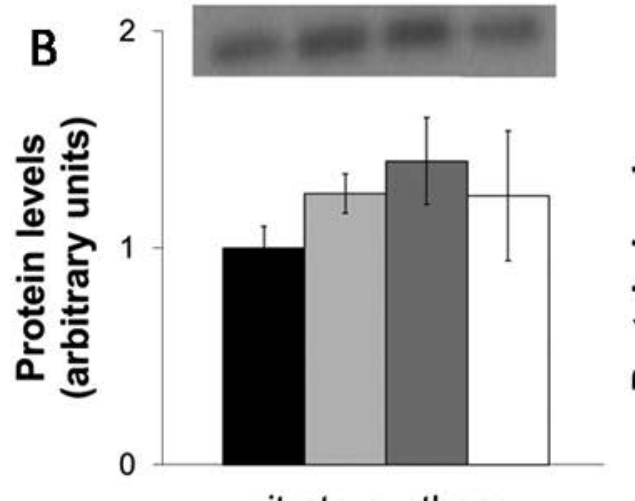

citrate synthase

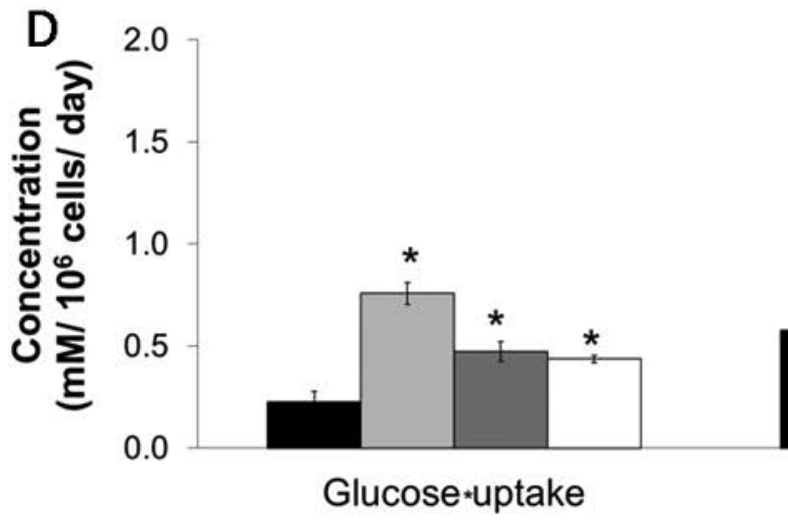

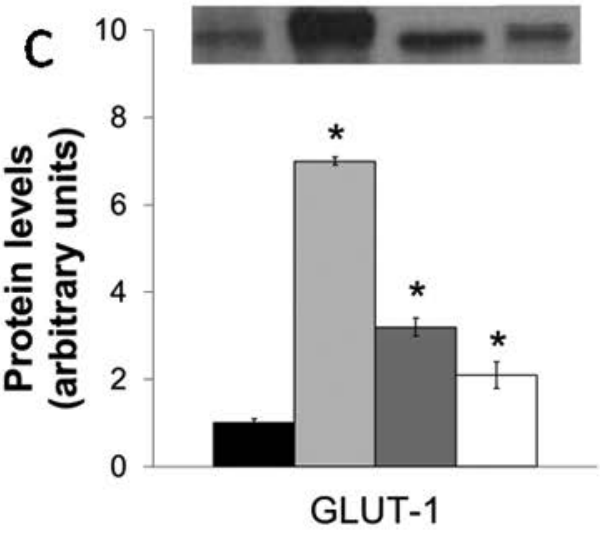

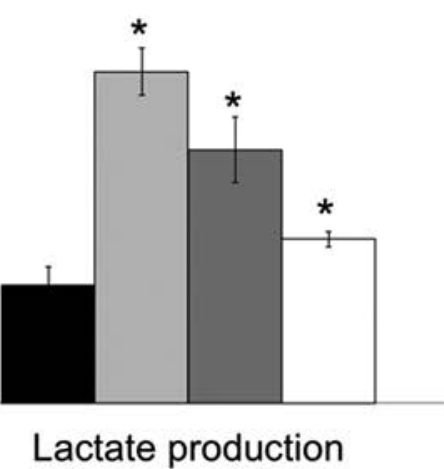

Figure 8. Metabolic adaptation of normoxic CDCs, hypoxic CDCs, and CDCs treated with $1 \mathrm{mM}$ DMOG and $30 \mu \mathrm{M}$ BIC for $24 \mathrm{~h}$. (A) Basal and FCCP-uncoupled respiration rates were reduced despite unchanged mitochondrial numbers indicated by (B) unchanged citrate synthase protein levels. (C) GLUT-1 protein expression, (D) levels of glucose uptake and production of lactate were increased, suggesting that hypoxic and PHDI-preconditioned cells switched to more glycolytic metabolism $(n=3)$. ${ }^{*} p<0.05$ vs. control. All experiments in this study used P2 CDCs at $70 \%$ to $80 \%$ confluency, unless otherwise stated.

progenitor cells will be administered to the hypoxic environment of the infarct scar.

Hypoxic-preconditioned CDCs showed increased expression of CXCR-4, indicating that preconditioning may stimulate cardiac stem cell homing to SDF-1 $\alpha$ overexpressed in the infarcted heart (68). Under hypoxia, CDCs showed a significant increase in the expression of EPO and VEGF, suggesting that hypoxic pretreatment would improve the cardiosphere's ability to trigger new blood vessel regeneration and restore vascular networks $(26,51)$. Notably, hypoxic CDCs had approximately $75 \%$ lower oxygen consumption and were able to switch to a more glycolytic metabolism, suggesting that they may be better adapted to survive within the hypoxic infarct scar, compared with normoxic CDCs. Implantation of the hypoxic CDCs into the infarcted mouse heart results in greater cell engraftment 
and better functional recovery than treatment with conventionally cultured (normoxic) CDCs (40).

\section{PHDI-Preconditioning Partly Mimicked the Effects of Hypoxic Preconditioning}

Our study is the first to use PHDIs to stabilize HIF in CDC culture and so mimic the effects of hypoxic CDC culture. Simulation of the hypoxic response using PHDIs could remove the necessity for culture in hypoxic incubators, prior to in vivo application of stem cells, provided the beneficial effects of hypoxic culture could be replicated pharmacologically. One of the advantages of stimulating a hypoxic response by using PHDIs was that manipulation using a pharmaceutical maybe more practical and specific to scale up rather than physiological manipulation of oxygen levels. Besides that, HIF- $1 \alpha$ has a biological half-life of only $\approx 5$ min under normoxic conditions (37). Its rapid proteosomal degradation upon exposure to ambient air (consisting of $21 \%$ oxygen) infers challenges during hypoxic cell culture maintenance. Intermittent hypoxic/normoxic condition might profoundly affect the stabilization of HIF-1 $\alpha$ in culture and introduce variability in the end product.

However, pharmacological drugs might induce cytotoxicity beyond threshold concentration; thus, a careful cytotoxicity test was performed in this study. The optimal treatment doses for the PHDIs with the CDCs, with respect to their optimum potential to activate HIF- $1 \alpha$ expression and negative cell apoptosis effects (cell numbers were not affected by PHDI treatment at these concentrations), were found to be $1 \mathrm{mM}$ DMOG or $30 \mu \mathrm{M}$ BIC for $24 \mathrm{~h}$. Furthermore, we selected these concentrations ( $1 \mathrm{mM}$ DMOG or $30 \mu \mathrm{M}$ BIC) because these doses significantly stabilized and activated HIF, and therefore induced metabolic changes and upregulation of important cytokines including CXCR-4 and EPO. In addition, both PHDIs significantly reduced the cardiac mesenchymal cell marker CD90, induced the expression of GLUT-1 protein, and glucose uptake and lactate production, and decreased cellular oxygen respiration, indicating that PHDI-preconditioned CDCs had adapted to the PHDIinduced "hypoxic" condition by reducing oxygen consumption and increasing glycolytic metabolism.

However, physiologically induced hypoxia and pharmacologically induced hypoxia resulted in different effects on CDCs. For example, hypoxic preconditioning increased the proliferation rate of adult CDCs above that of cells cultured under normoxia over $96 \mathrm{~h}$, but this effect was not observed in PHDI-preconditioned cells after the initial $24 \mathrm{~h}$. Cells cultured under hypoxia continued to proliferate beyond confluence, forming sheets that were several cells in thickness, and this was not seen with the PHDI-treated CDCs. Furthermore, while DMOG-treated
CDCs had significantly increased c-Kit, EPO, and VEGF mRNA expression, BIC treatment did not increase VEGF mRNA expression. The different responses of CDCs to hypoxic or PHDI preconditioning could be due to variations in the ability of hypoxia or the PHDIs to activate the HIF system. Tian et al. (66) reported that exposure of cells to different levels of hypoxia showed markedly different effects on each site of hydroxylation. They found that while culture under $1 \%$ oxygen almost completely suppressed prolyl hydroxylation (Pro402 and Pro564) only $40 \%$ of asparaginyl (Asn803) hydroxylation was suppressed under this condition. The asparaginyl (Asn803) hydroxylation that persisted at $1 \%$ oxygen was only suppressed at a lower oxygen level $(0.2 \%)$.

Analysis of two different types of PHDIs also permitted comparison of the differential sensitivity of these inhibitors toward HIF hydroxylation. Both of the compounds used in this study, DMOG and BIC, are effective inhibitors of HIF hydroxylases. However, they act by different mechanisms. DMOG is a generic $20 \mathrm{O}$ analog, which can inhibit other members of the superfamily of 2OG-dependent dioxygenases, which is a diverse family with important functions, including DNA repair and matrix metabolism. Importantly, in an expression analysis of the effect of DMOG in cultured cells (66), DMOG was more effective at suppressing HIF asparaginyl hydroxylation compared to HIF prolyl hydroxylation. In contrast, BIC specifically inhibited prolyl hydroxylation but did not affect asparaginyl hydroxylation, resulting in an incomplete HIF activation. This is in agreement with our data, which showed that BIC-treated CDCs had a significantly lower HIF-1 $\alpha$ level, compared with hypoxic CDCs and DMOG-treated CDCs, resulting in different effects on $\mathrm{CDC}$ genotypic and phenotypic levels observed between the hypoxic preconditioning and PHDI-preconditioning cells.

\section{CONCLUSION}

Hypoxic treatment significantly increased CDC proliferation, shortening the time required to obtain adequate cell numbers for therapy, while both hypoxic and PHDI preconditioning enhanced the therapeutic potential of CDCs by increasing the expression of CXCR-4, EPO, and VEGF. Hypoxic and PHDI-preconditioned CDCs had reduced oxygen consumption rates, suggesting that treated cells could survive better after transplantation into the hypoxic infarcted myocardium.

ACKNOWLEDGMENTS: This work was supported by the British Heart Foundation (grant Nos.: PG/07/059/23259 and PG/13/34/30216). Christopher Schofield is funded by the European Research Council, and Lisa Heather is funded by Diabetes UK (grant No. 11/0004175). We thank Emma Carter for technical support. Suat Cheng Tan and Kar Kheng Yeoh thank the Malaysian Ministry of Higher Education and Universiti Sains Malaysia for fellowships. The authors declare no conflict of interest. 


\section{REFERENCES}

1. Allsopp, R. C.; Cheshier, S.; Weissman, I. L. Telomere shortening accompanies increased cell cycle activity during serial transplantation of hematopoietic stem cells. J. Exp. Med. 193(8):917-924; 2001.

2. Anversa, P.; Sussman, M. A.; Bolli, R. Molecular genetic advances in cardiovascular medicine: Focus on the myocyte. Circulation 109(23):2832-2838; 2004.

3. Asikainen, T. M.; Ahmad, A.; Schneider, B. K.; Ho, W. B.; Arend, M.; Brenner, M.; Gunzler, V.; White, C. W. Stimulation of HIF-1alpha, HIF-2alpha, and VEGF by prolyl 4-hydroxylase inhibition in human lung endothelial and epithelial cells. Free Radic. Biol. Med. 38(8):1002-1013; 2005.

4. Beltrami, A. P.; Barlucchi, L.; Torella, D.; Baker, M.; Limana, F.; Chimenti, S.; Kasahara, H.; Rota, M.; Musso, E.; Urbanek, K.; Leri, A.; Kajstura, J.; Nadal-Ginard, B.; Anversa, P. Adult cardiac stem cells are multipotent and support myocardial regeneration. Cell 114(6):763-776; 2003.

5. Blackburn, E. H. Structure and function of telomeres. Nature 350(6319):569-573; 1991.

6. Cadenas, S.; Aragones, J.; Landazuri, M. O. Mitochondrial reprogramming through cardiac oxygen sensors in ischaemic heart disease. Cardiovasc. Res. 88(2):219-228; 2010.

7. Carr, C. A.; Stuckey, D. J.; Tan, J. J.; Tan, S. C.; Gomes, R. S.; Camelliti, P.; Messina, E.; Giacomello, A.; Ellison, G. M.; Clarke, K. Cardiosphere-derived cells improve function in the infarcted rat heart for at least 16 weeks--An MRI study. PLoS One 6(10):e25669; 2011.

8. Chen, X.; Tian, Y.; Yao, L.; Zhang, J.; Liu, Y. Hypoxia stimulates proliferation of rat neural stem cells with influence on the expression of cyclin D1 and c-Jun N-terminal protein kinase signaling pathway in vitro. Neuroscience 165(3):705-714; 2010.

9. Cheng, K.; Ibrahim, A.; Hensley, M. T.; Shen, D.; Sun, B.; Middleton, R.; Liu, W.; Smith, R. R.; Marban, E. Relative roles of CD90 and c-kit to the regenerative efficacy of cardiosphere-derived cells in humans and in a mouse model of myocardial infarction. J. Am. Heart Assoc. 3(5):e001260; 2014.

10. Chimenti, I.; Smith, R. R.; Li, T. S.; Gerstenblith, G.; Messina, E.; Giacomello, A.; Marban, E. Relative roles of direct regeneration versus paracrine effects of human cardiosphere-derived cells transplanted into infarcted mice. Circ. Res. 106(5):971-980; 2010.

11. Chowdhury, R.; Hardy, A.; Schofield, C. J. The human oxygen sensing machinery and its manipulation. Chem. Soc. Rev. 37(7):1308-1319; 2008.

12. ClinicalTrials.gov. NCT00456053: A randomized study of the safety and efficacy of FG-2216 in subjects with renal anemia not requiring dialysis and not receiving recombinant human erythropoietin. https://clinicaltrials.gov/ct2/ show/NCT00456053; 2007.

13. Coussens, M.; Davy, P.; Brown, L.; Foster, C.; Andrews, W. H.; Nagata, M.; Allsopp, R. RNAi screen for telomerase reverse transcriptase transcriptional regulators identifies HIF1alpha as critical for telomerase function in murine embryonic stem cells. Proc. Natl. Acad. Sci. USA 107(31):13842-13847; 2010.

14. Covello, K. L.; Kehler, J.; Yu, H.; Gordan, J. D.; Arsham, A. M.; Hu, C. J.; Labosky, P. A.; Simon, M. C.; Keith, B. HIF-2alpha regulates Oct-4: Effects of hypoxia on stem cell function, embryonic development, and tumor growth. Genes Dev. 20(5):557-570; 2006.
15. Csete, M. Oxygen in the cultivation of stem cells. Ann. N. Y. Acad. Sci. 1049:1-8; 2005.

16. Cummins, E. P.; Seeballuck, F.; Keely, S. J.; Mangan, N. E.; Callanan, J. J.; Fallon, P. G.; Taylor, C. T. The hydroxylase inhibitor dimethyloxalylglycine is protective in a murine model of colitis. Gastroenterology 134(1):156-165; 2008.

17. Ellison, G. M.; Vicinanza, C.; Smith, A. J.; Aquila, I.; Leone, A.; Waring, C. D.; Henning, B. J.; Stirparo, G. G.; Papait, R.; Scarfo, M.; Agosti, V.; Viglietto, G.; Condorelli, G.; Indolfi, C.; Ottolenghi, S.; Torella, D.; Nadal-Ginard, B. Adult c-kit(pos) cardiac stem cells are necessary and sufficient for functional cardiac regeneration and repair. Cell 154(4):827-842; 2013.

18. FibroGen. FibroGen investigational small molecule anemia therapy, FG-2216, increased endogenous EPO production in humans. St. Louis, MO; http://investor.fibrogen.com/phoenix. $\mathrm{zhtml}$ ? $=253783 \& \mathrm{p}=$ irol-news Article $\&$ ID $=1984287$; 2004.

19. Forristal, C. E.; Wright, K. L.; Hanley, N. A.; Oreffo, R. O.; Houghton, F. D. Hypoxia inducible factors regulate pluripotency and proliferation in human embryonic stem cells cultured at reduced oxygen tensions. Reproduction 139(1):85-97; 2010.

20. French, B. A.; Kramer, C. M. Mechanisms of post-infarct left ventricular remodeling. Drug Discov. Today Dis. Mech. 4(3):185-196; 2007.

21. Gambini, E.; Pompilio, G.; Biondi, A.; Alamanni, F.; Capogrossi, M. C.; Agrifoglio, M.; Pesce, M. C-kit+ cardiac progenitors exhibit mesenchymal markers and preferential cardiovascular commitment. Cardiovasc. Res. 89(2): 362-373; 2011.

22. Grayson, W. L.; Zhao, F.; Bunnell, B.; Ma, T. Hypoxia enhances proliferation and tissue formation of human mesenchymal stem cells. Biochem. Biophys. Res. Commun. 358(3):948-953; 2007.

23. Groenman, F. A.; Rutter, M.; Wang, J.; Caniggia, I.; Tibboel, D.; Post, M. Effect of chemical stabilizers of hypoxiainducible factors on early lung development. Am. J. Physiol. Lung Cell Mol. Physiol. 293(3):557-567; 2007.

24. Heather, L. C.; Cole, M. A.; Lygate, C. A.; Evans, R. D.; Stuckey, D. J.; Murray, A. J.; Neubauer, S.; Clarke, K. Fatty acid transporter levels and palmitate oxidation rate correlate with ejection fraction in the infarcted rat heart. Cardiovasc. Res. 72(3):430-437; 2006.

25. Hierlihy, A. M.; Seale, P.; Lobe, C. G.; Rudnicki, M. A.; Megeney, L. A. The post-natal heart contains a myocardial stem cell population. FEBS Lett. 530(1-3):239-243; 2002.

26. Hoeben, A.; Landuyt, B.; Highley, M. S.; Wildiers, H.; Van Oosterom, A. T.; De Bruijn, E. A. Vascular endothelial growth factor and angiogenesis. Pharmacol. Rev. 56(4):549-580; 2004.

27. Hsiao, L. C.; Carr, C.; Chang, K. C.; Lin, S. Z.; Clarke, K. Stem cell-based therapy for ischemic heart disease. Cell Transplant. 22(4):663-675; 2013.

28. Hsiao, L. C.; Perbellini, F.; Gomes, R. S.; Tan, J. J.; Vieira, S.; Faggian, G.; Clarke, K.; Carr, C. A. Murine cardiosphere-derived cells are impaired by age but not by cardiac dystrophic dysfunction. Stem Cells Dev. 23(9): 1027-1036; 2014.

29. Hsieh, M. M.; Linde, N. S.; Wynter, A.; Metzger, M.; Wong, C.; Langsetmo, I.; Lin, A.; Smith, R.; Rodgers, G. P.; Donahue, R. E. Klaus, S. J.; Tisdale, J. F. HIF prolyl hydroxylase inhibition results in endogenous erythropoietin induction, 
erythrocytosis, and modest fetal hemoglobin expression in rhesus macaques. Blood 110(6):2140-2147; 2007.

30. Ingraham, C. A.; Park, G. C.; Makarenkova, H. P.; Crossin, K. L. Matrix metalloproteinase (MMP)-9 induced by Wnt signaling increases the proliferation and migration of embryonic neural stem cells at low $\mathrm{O}_{2}$ levels. J. Biol. Chem. 286(20):17649-17657; 2011.

31. Ji, L.; Liu, Y. X.; Yang, C.; Yue, W.; Shi, S. S.; Bai, C. X.; Xi, J. F.; Nan, X.; Pei, X. T. Self-renewal and pluripotency is maintained in human embryonic stem cells by co-culture with human fetal liver stromal cells expressing hypoxia inducible factor 1 alpha. J. Cell. Physiol. 221(1):54-66; 2009.

32. Johnston, P. V.; Sasano, T.; Mills, K.; Evers, R.; Lee, S. T.; Smith, R. R.; Lardo, A. C.; Lai, S. H.; Steenbergen, C.; Gerstenblith, G.; Lange, R.; Marban, E. Engraftment, differentiation and functional benefits of autologous cardiosphere-derived cells in porcine ischemic cardiomyopathy. Circulation 120(12):1075-1095; 2009.

33. Katsara, O.; Mahaira, L. G.; Iliopoulou, E. G.; Moustaki, A.; Antsaklis, A.; Loutradis, D.; Stefanidis, K.; Baxevanis, C. N.; Papamichail, M.; Perez, S. A. Effects of donor age, gender, and in vitro cellular aging on the phenotypic, functional, and molecular characteristics of mouse bone marrow-derived mesenchymal stem cells. Stem Cells Dev. 20(9):1549-1561; 2011.

34. Kimura, W.; Sadek, H. A. The cardiac hypoxic niche: Emerging role of hypoxic microenvironment in cardiac progenitors. Cardiovasc. Diagn. Ther. 2(4):278-289; 2012.

35. Koninckx, R.; Daniels, A.; Windmolders, S.; Carlotti, F.; Mees, U.; Steels, P.; Rummens, J. L.; Hendrikx, M.; Hensen, K. Mesenchymal stem cells or cardiac progenitors for cardiac repair? A comparative study. Cell. Mol. Life Sci. 68(12):2141-2156; 2011.

36. Lee, E. Y.; Xia, Y.; Kim, W. S.; Kim, M. H.; Kim, T. H.; Kim, K. J.; Park, B. S.; Sung, J. H. Hypoxia-enhanced woundhealing function of adipose-derived stem cells: Increase in stem cell proliferation and up-regulation of VEGF and bFGF. Wound Repair Regen. 17(4):540-547; 2009.

37. Lee, J. W.; Bae, S. H.; Jeong, J. W.; Kim, S. H.; Kim, K. W. Hypoxia-inducible factor (HIF-1) alpha: Its protein stability and biological functions. Exp. Mol. Med. 36(1):1-12; 2004.

38. Lennon, D. P.; Edmison, J. M.; Caplan, A. I. Cultivation of rat marrow-derived mesenchymal stem cells in reduced oxygen tension: Effects on in vitro and in vivo osteochondrogenesis. J. Cell. Physiol. 187(3):345-355; 2001.

39. Li, L.; Xie, T. Stem cell niche: Structure and function. Annu. Rev. Cell Dev. Biol. 21:605-631; 2005.

40. Li, T. S.; Cheng, K.; Malliaras, K.; Matsushita, N.; Sun, B.; Marban, L.; Zhang, Y.; Marban, E. Expansion of human cardiac stem cells in physiological oxygen improves cell production efficiency and potency for myocardial repair. Cardiovasc. Res. 89(1):157-165; 2011.

41. Lienard, B. M.; Conejo-Garcia, A.; Stolze, I.; Loenarz, C.; Oldham, N. J.; Ratcliffe, P. J.; Schofield, C. J. Evaluation of aspirin metabolites as inhibitors of hypoxia-inducible factor hydroxylases. Chem. Commun. 47:6393-6395; 2008.

42. Lisy, K.; Peet, D. J. Turn me on: Regulating HIF transcriptional activity. Cell Death Differ. 15(4):642-649; 2008.

43. Liu, L.; Rando, T. A. Manifestations and mechanisms of stem cell aging. J. Cell Biol. 193(2):257-266; 2011.

44. Makkar, R. R.; Smith, R. R.; Cheng, K.; Malliaras, K.; Thomson, L. E.; Berman, D.; Czer, L. S.; Marban, L.; Mendizabal, A.; Johnston, P. V.; Russell, S. D.; Schuleri, K. H.;
Lardo, A. C.; Gerstenblith, G.; Marban, E. Intracoronary cardiosphere-derived cells for heart regeneration after myocardial infarction (CADUCEUS): A prospective, randomised phase 1 trial. Lancet 379(9819):895-904; 2012.

45. Masson, N.; Singleton, R. S.; Sekirnik, R.; Trudgian, D. C.; Ambrose, L. J.; Miranda, M. X.; Tian, Y. M.; Kessler, B. M.; Schofield, C. J.; Ratcliffe, P. J. The FIH hydroxylase is a cellular peroxide sensor that modulates HIF transcriptional activity. EMBO Rep. 13(3):251-257; 2012.

46. Messina, E.; De Angelis, L.; Frati, G.; Morrone, S.; Chimenti, S.; Fiordaliso, F.; Salio, M.; Battaglia, M.; Latronico, M. V.; Coletta, M.; Vivarelli, E.; Frati, L.; Cossu, G.; Giacomello, A. Isolation and expansion of adult cardiac stem cells from human and murine heart. Circ. Res. 95(9):911-921; 2004.

47. Miyamoto, S.; Kawaguchi, N.; Ellison, G. M.; Matsuoka, R.; Shin'oka, T.; Kurosawa, H. Characterization of long-term cultured c-kit+ cardiac stem cells derived from adult rat hearts. Stem Cells Dev. 19(1):105-116; 2010.

48. Murray, A. J.; Cole, M. A.; Lygate, C. A.; Carr, C. A.; Stuckey, D. J.; Little, S. E.; Neubauer, S.; Clarke, K. Increased mitochondrial uncoupling proteins, respiratory uncoupling and decreased efficiency in the chronically infarcted rat heart. J. Mol. Cell. Cardiol. 44(4):694-700; 2008.

49. Oh, H.; Bradfute, S. B.; Gallardo, T. D.; Nakamura, T.; Gaussin, V.; Mishina, Y.; Pocius, J.; Michael, L. H.; Behringer, R. R.; Garry, D. J.; Entman, M. L.; Schneider, M. D. Cardiac progenitor cells from adult myocardium: Homing, differentiation, and fusion after infarction. Proc. Natl. Acad. Sci. USA 100(21):12313-12318; 2003.

50. Peterson, W. J.; Tachiki, K. H.; Yamaguchi, D. T. Serial passage of MC3T3-E1 cells down-regulates proliferation during osteogenesis in vitro. Cell Prolif. 37(5):325-336; 2004.

51. Pugh, C. W.; Ratcliffe, P. J. Regulation of angiogenesis by hypoxia: Role of the HIF system. Nat. Med. 9(6):677-684; 2003.

52. Rehman, J.; Traktuev, D.; Li, J.; Merfeld-Clauss, S.; TemmGrove, C. J.; Bovenkerk, J. E.; Pell, C. L.; Johnstone, B. H.; Considine, R. V.; March, K. L. Secretion of angiogenic and antiapoptotic factors by human adipose stromal cells. Circulation 109(10):1292-1298; 2004.

53. Rodesch, F.; Simon, P.; Donner, C.; Jauniaux, E. Oxygen measurements in endometrial and trophoblastic tissues during early pregnancy. Obstet. Gynecol. 80(2):283-285; 1992.

54. Scadden, D. T. The stem-cell niche as an entity of action. Nature 441(7097):1075-1079; 2006.

55. Schuh, R. A.; Jackson, K. C.; Khairallah, R. J.; Ward, C. W.; Spangenburg, E. E. Measuring mitochondrial respiration in intact single muscle fibers. Am. J. Physiol. Regul. Integr. Comp. Physiol. 302(6):712-719; 2012.

56. Semenza, G. L.; Wang, G. L. A nuclear factor induced by hypoxia via de novo protein synthesis binds to the human erythropoietin gene enhancer at a site required for transcriptional activation. Mol. Cell. Biol. 12(12):5447-5454; 1992.

57. Siddappa, R.; Licht, R.; van Blitterswijk, C.; de Boer, J. Donor variation and loss of multipotency during in vitro expansion of human mesenchymal stem cells for bone tissue engineering. J. Orthop. Res. 25(8):1029-1041; 2007.

58. Simon, M. C.; Keith, B. The role of oxygen availability in embryonic development and stem cell function. Nat. Rev. Mol. Cell Biol. 9(4):285-296; 2008.

59. Smith, A. J.; Lewis, F. C.; Aquila, I.; Waring, C. D.; Nocera, A.; Agosti, V.; Nadal-Ginard, B.; Torella, D.; Ellison, G. M. Isolation and characterization of resident endogenous 
c-Kit(+) cardiac stem cells from the adult mouse and rat heart. Nat. Protoc. 9(7):1662-1681; 2014.

60. Smith, R. R.; Barile, L.; Cho, H. C.; Leppo, M. K.; Hare, J. M.; Messina, E.; Giacomello, A.; Abraham, M. R.; Marban, E. Regenerative potential of cardiosphere-derived cells expanded from percutaneous endomyocardial biopsy specimens. Circulation 115(7):896-908; 2007.

61. Soonpaa, M. H.; Field, L. J. Survey of studies examining mammalian cardiomyocyte DNA synthesis. Circ. Res. 83(1):15-26; 1998.

62. Studer, L.; Csete, M.; Lee, S. H.; Kabbani, N.; Walikonis, J.; Wold, B.; McKay, R. Enhanced proliferation, survival, and dopaminergic differentiation of CNS precursors in lowered oxygen. J. Neurosci. 20(19):7377-7383; 2000.

63. Tan, S. C.; Carr, C. A.; Yeoh, K. K.; Schofield, C. J.; Davies, K. E.; Clarke, K. Identification of valid housekeeping genes for quantitative RT-PCR analysis of cardiosphere-derived cells preconditioned under hypoxia or with prolyl-4-hydroxylase inhibitors. Mol. Biol. Rep. 39(4):4857-4867; 2012.

64. Tang, Y. L.; Shen, L.; Qian, K.; Phillips, M. I. A novel twostep procedure to expand cardiac Sca-1+ cells clonally. Biochem. Biophys. Res. Commun. 359(4):877-883; 2007.

65. Theus, M. H.; Wei, L.; Cui, L.; Francis, K.; Hu, X.; Keogh, C.; Yu, S. P. In vitro hypoxic preconditioning of embryonic stem cells as a strategy of promoting cell survival and functional benefits after transplantation into the ischemic rat brain. Exp. Neurol. 210(2):656-670; 2008.
66. Tian, Y. M.; Yeoh, K. K.; Lee, M. K.; Eriksson, T.; Kessler, B. M.; Kramer, H. B.; Edelmann, M. J.; Willam, C.; Pugh, C. W.; Schofield, C. J.; Ratcliffe, P. J. Differential sensitivity of hypoxia inducible factor hydroxylation sites to hypoxia and hydroxylase inhibitors. J. Biol. Chem. 286(15):13041$13051 ; 2011$.

67. van Berlo, J. H.; Kanisicak, O.; Maillet, M.; Vagnozzi, R. J.; Karch, J.; Lin, S. C.; Middleton, R. C.; Marban, E.; Molkentin, J. D. c-kit+ cells minimally contribute cardiomyocytes to the heart. Nature 509(7500):337-341; 2014.

68. Wang, K.; Zhao, X.; Kuang, C.; Qian, D.; Wang, H.; Jiang, H.; Deng, M.; Huang, L. Overexpression of SDF1alpha enhanced migration and engraftment of cardiac stem cells and reduced infarcted size via CXCR4/PI3K pathway. PLoS One 7(9):e43922; 2012.

69. Waterstrat, A.; Van Zant, G. Effects of aging on hematopoietic stem and progenitor cells. Curr. Opin. Immunol. 21(4):408-413; 2009.

70. Wu, K. J.; Grandori, C.; Amacker, M.; Simon-Vermot, N.; Polack, A.; Lingner, J.; Dalla-Favera, R. Direct activation of TERT transcription by c-MYC. Nat. Genet. 21(2):220$224 ; 1999$.

71. Zhao, T.; Huang, X.; Zhu, L. L.; Xiong, L.; Zhang, K.; Wu, L. Y.; Liu, B.; Wu, K. W.; Fan, M. Effect of low glucose and/or hypoxia on the proliferation and metabolism of neural stem cells. Zhongguo Ying Yong Sheng Li Xue Za Zhi 26(4):412-415; 2010 . 